\title{
Natural convection during melting in vertical finned tube latent thermal energy storage systems
}

\author{
J. Vogel ${ }^{*}$, M. Johnson ${ }^{\dagger}$ \\ German Aerospace Center (DLR), Pfaffenwaldring 38-40, 70569 Stuttgart, Germany
}

\begin{abstract}
Natural convection can have a major impact on the melting process during charging in a latent heat storage system. Heat transfer enhancement by natural convection depends strongly on the dimensions, material properties and boundary conditions of the storage system. In complex geometries, such as shell-and-tube storage systems with extended fins, a good approximation of the impact of natural convection on the melting process is very difficult. There are no correlations for such geometries, and simulations of these storage systems require extensive computational effort. In the present work, we analyzed the impact of natural convection in four vertical shell-and-tube extended fin systems with a common tube height. To investigate the influence of the tube height, one of the fins was additionally modeled with two further tube heights.

We scaled the resulting liquid fraction evolutions into a dimensionless form and used a convective enhancement factor to assess the strength of natural convection. A linear fit function for the mean convective enhancement factor was derived to estimate the melting process considering natural convection. With it, natural convection may be incorporated into the design process of storage systems to optimize the charging time.

The results indicate a negligible impact of natural convection in fins with a small tube spacing and a high fin fraction. There is a considerable impact from natural convection in fins designed with a large tube spacing and a low fin fraction. However, large fin heights lead to decreased heat transfer enhancement by natural convection.
\end{abstract}

\section{Keywords}

Heat transfer; Phase change material (PCM); Finned tube heat exchanger; Computational fluid dynamics (CFD); Convective enhancement factor

\footnotetext{
* First corresponding author: julian.r.vogel@gmail.com, ORCID ID: https://orcid.org/0000-0001-9792-2332

† Second corresponding author: maike.johnson@dlr.de
} 


\section{Nomenclature}

Latin

A aspect ratio, $A=H / W$

$a$ thermal diffusivity, $[a]=\mathrm{m}^{2} / \mathrm{s}$

$B$ momentum source coefficient, $[B]=(\mathrm{Pa} \mathrm{s}) / \mathrm{m}^{2}$

$C \quad$ mushy zone constant, $[C]=(\mathrm{Pa} \mathrm{s}) / \mathrm{m}^{2}$

$c_{p} \quad$ specific isobaric heat capacity, $\left[c_{p}\right]=\mathrm{J} /(\mathrm{kg} \mathrm{K})$

$D_{t} \quad$ tube distance, $\left[D_{t}\right]=\mathrm{m}$

$\hat{\boldsymbol{e}}_{y} \quad$ unit vector in $y$-direction

$\boldsymbol{F}_{b} \quad$ buoyancy term, $\left[\boldsymbol{F}_{b}\right]=\mathrm{Pa} / \mathrm{m}$

Fo Fourier number

$f_{\mathrm{l}} \quad$ liquid phase fraction

$g$ gravity constant, $[g]=\mathrm{m} / \mathrm{s}^{2}$

$H \quad$ height, $[H]=\mathrm{m}$

$h \quad$ specific enthalpy, $[h]=\mathrm{J} / \mathrm{kg}$

$k$ thermal conductivity, $[k]=\mathrm{W} /(\mathrm{m} \mathrm{K})$

$p \quad$ pressure, $[p]=\mathrm{Pa}$

$\dot{Q} \quad$ heat transfer rate, $[\dot{Q}]=\mathrm{W}$

$q^{\prime \prime} \quad$ heat flux, $\left[q^{\prime \prime}\right]=\mathrm{kW} / \mathrm{m}^{2}$

$L \quad$ latent heat, $[L]=\mathrm{kJ} / \mathrm{kg}$

$R a \quad$ Rayleigh number

$S_{h} \quad$ source term in energy equation, $\left[S_{h}\right]=\mathrm{W} / \mathrm{m}^{3}$

$\boldsymbol{S}_{\boldsymbol{u}} \quad$ source term in momentum equation, $\left[\boldsymbol{S}_{\boldsymbol{u}}\right]=\mathrm{Pa} / \mathrm{m}$

Ste Stefan number

$T$ temperature, $[T]={ }^{\circ} \mathrm{C}$

$t \quad$ time, $[t]=\mathrm{s}$

Pr Prandtl number

$\boldsymbol{u} \quad$ velocity vector, $\boldsymbol{u}=(u, v, w)^{\top}$

$u \quad x$-velocity, $[u]=\mathrm{m} / \mathrm{s}$

$v \quad y$-velocity, $[v]=\mathrm{m} / \mathrm{s}$

$$
\begin{array}{ll}
w & z \text {-velocity, }[w]=\mathrm{m} / \mathrm{s} \\
W & \text { width, }[W]=\mathrm{m} \\
x, y, z & \text { coordinates, }[x, y, z]=\mathrm{m}
\end{array}
$$

Greek

$\beta \quad$ thermal expansion coefficient, $[\beta]=1 / \mathrm{K}$

$\varepsilon \quad$ convective enhancement factor

$\mu \quad$ dynamic viscosity, $[\mu]=$ Pa s

$v \quad$ kinematic viscosity, $[v]=\mathrm{m}^{2} / \mathrm{s}$

$\xi \quad$ half melting range in melting point model, $[\xi]={ }^{\circ} \mathrm{C}$

$\rho \quad$ density, $[\rho]=\mathrm{kg} / \mathrm{m}^{3}$

\section{Subscripts}

$0 \quad$ initial value

cond conduction

conv convection

1 liquid

lat latent heat content

m melting point

max maximum

ref reference

s solid

sens sensible heat content

w wall

\section{Symbols}

$\nabla \quad$ nabla operator: $\nabla=(\partial / \partial x, \partial / \partial y, \partial / \partial z)$

$\Delta \quad$ finite difference

\section{Introduction}

Climate change and its consequences are becoming increasingly evident [1]. Sustainable energy sources and largescale energy storage are part of a solution to stop climate change. An important contribution to the future energy mix is thermal energy storage [2]. A goal with thermal energy storage is to make use of low cost and sustainable storage materials to implement large storage capacities and supply energy flexibly. In a thermal energy storage with a phase change on the storage material side, the latent heat of fusion stores large amounts of energy per unit volume in a narrow temperature range. There are various concepts for storing thermal energy in phase change materials (PCMs), discussed in general in [3]. The concept discussed in this paper is the shell-and-tube storage concept. This concept has been discussed by several authors, including a clipped fin and a large-scale design by Laing et al. [4], an exterior clamped fin discussed by Walter et al. [5] and a large-scale design discussed by Garcia et al. [6].

The storage material is selected based on a range of criteria [7], including the melting temperature, which needs to be paired with the system into which the unit is being integrated. Many applicable storage materials have a low thermal conductivity. This especially limits heat transfer during solidification, during which natural convection is not possible in the solid layer forming at the heat sink. While melting a PCM, natural convection increases heat transfer when dimensions, material properties and boundary conditions allow for it.

To overcome the low thermal conductivity of PCMs, one concept is to increase the surface area of the heat exchanger, as discussed in the review papers by Jegadheeswaran and Pokehar [8], Agyenim et al. [9], Liu et al. [10] and Gasia et al. [11]. In a vertical shell-and-tube arrangement, the surface areas of the tubes can be extended with fins made of a highly thermally conductive material. Several designs of finned tubes have been examined, including a branched design by Walter et al. [5], a plate design by Laing et al. [12] and a different branched design by Johnson et al. [13]. From these, especially axially extruded fins are promising, because they have low manufacturing costs, high stability and the vertical chambers between fins allow for natural convection heat transfer and density change during phase change.

The challenge in designing a finned shell-and-tube PCM heat exchanger is to find an optimal tradeoff (for a given set of capacity and power parameters) between tube distance, fin fraction, fin thickness, fin surface area, and fin distribution and shape throughout the domain, as well as considering physical details such as manufacturability and attachment methods. All of these parameters influence the performance, i.e. the heat 
transfer rate, of a heat exchanger design. In this type of heat exchanger design, the resulting heat transfer rate is dominated by either heat conduction or natural convection.

However, the influence of natural convection in phase change materials is not fully understood. The influence of natural convection during melting of a PCM in simple geometries has been studied by many researchers. An overview is given by Dhaidan and Khodadadi [14]. Further research on melting in rectangular geometries was done e.g. by Bareiss and Beer [15], Bénard et al. [16], Jany and Bejan [17], Farid and Husian [18], Shatikian et al. [19,20] and Vogel et al. [21].

During solidification, there is only a minor influence of natural convection. The solidification process was studied, for example, by Pointner et al. [22] and the difference of the melting and solidification processes was investigated by Vogel et al. [21], both for a flat plate storage system.

A shell and tube system with radial plate fins was analyzed including the effect of natural convection during solidification and melting by Muhammad and Badr [23]. However, results of multiple fins including axial designs and the heat transfer enhancement due to natural convection were not part of their work.

A topology optimization approach of fin designs including the effect of natural convection was presented by Pizzolato et al. [24] and Pizzolato et al. [25]. . However, their work does not show the actual heat transfer enhancement due to natural convection in applied fin designs and the fundamental optimization approach restricts the applicable manufacturing methods.

Thorough investigations on the impact of natural convection in practically used three-dimensional vertical fin designs are not available in literature. It is clear that the heat transfer enhancement of natural convection depends on the dimensions of the PCM space between the fins. However, the degree of influence and the spacing between the fins is not clear. Currently, therefore, either the influence of natural convection is neglected in the design phase, or computationally extensive CFD analyses have to be conducted for each new storage design.

To gain a better understanding of the design factors which influence natural convection, we investigated melting of a PCM in several different fin designs and the influence of natural convection on their performance. All four designs were first modelled with the same tube height in three dimensional numerical simulations in ANSYS ${ }^{\odot}$ Fluent [26]. To reduce the large computational effort, only a small height section was examined. In addition, for one of the designs, two additional heights were analyzed.

This article first describes the four fin designs in section 2 and the numerical model in section 3 . The results are visualized and quantitatively analyzed in section 4 and discussed in section 5. Our conclusions and outlook follow in section 6 .

The purpose of this article is to find the impact of natural convection on heat transfer during melting exemplarily for the four presented fin designs. Therefore, a convective enhancement factor is calculated that compares the solution with natural convection to a hypothetical solution with only heat conduction, as described by Vogel et al. [21]. With this convective enhancement factor, natural convection may be incorporated in the design process of latent thermal energy storage (LTES) systems to optimize the charging time, therefore improving the design process.

\section{Description of fin designs}

The fins are distinguished by their different geometries, the tube spacing $D_{\mathrm{t}}$ and the fin-PCM fraction:

$f_{\text {fin }}=\frac{V_{\text {fin }}}{V_{\text {fin }}+V_{\text {PCM }}}$.

The first design, called "Organic" here, was designed for maximum power levels and has a small tube spacing of $D_{\mathrm{t}}=70 \mathrm{~mm}$ and a high fin volume fraction of $f_{\text {fin }}=17.9 \%$, see Figure $1 \mathrm{a}$ ). The design is discussed by Johnson et al in [13] and the integration in [27]. The second design, "Plate", was designed by Laing et al [28] with a tube spacing of $D_{\mathrm{t}}=$ $100 \mathrm{~mm}$ and a fin volume fraction of $f_{\text {fin }}=8.2 \%$, see Figure $1 \mathrm{~b})$. The third design, called "Snowflake" here, was designed by Laing et al. [4] with an intermediate tube spacing of $D_{\mathrm{t}}=160 \mathrm{~mm}$ and a fin volume fraction of $f_{\text {fin }}=14.3 \%$, see Figure $1 \mathrm{c}$ ). The fourth fin design, "Eco", was designed by Hübner et al. [29] with a large tube spacing of $D_{\mathrm{t}}=230 \mathrm{~mm}$ and a lower fin volume fraction of $f_{\text {fin }}=9.0 \%$, see Figure $1 \mathrm{~d})$. This design was optimized with a techno-economic analysis for maximum cost efficiency for integration in a solar thermal power plant with direct steam generation. The fin design parameters are given in Table 1.

Table 1: Fin design definition parameters.

\begin{tabular}{lcccc}
\hline Parameter & Organic & Plate & Snowflake & Eco \\
\hline Type & Axial & Radial & Axial & Axial \\
Tube spacing $D_{\mathrm{t}} / \mathrm{mm}$ & 70 & 100 & 160 & 230 \\
Height & 100 & 100 & 100 & $50,100,200$ \\
Inner tube diameter & 12.6 & 15.8 & 16.7 & 22.3 \\
$d_{\mathrm{i}} / \mathrm{mm}$ & 17.9 & 8.2 & 14.3 & 9.0 \\
Fin fraction $f_{\text {fin }} / \%$ & &
\end{tabular}

Numerical simulations of all designs were performed with CFD-models in ANSYS ${ }^{\odot}$ Fluent [26]. Due to the large computational effort of the model in combination with complex geometries, only a small height section was examined. This is relevant for the analysis of the results and the conclusions that can be drawn, since natural convection depends on the height of the occurring liquid phase volumes [21]. For fin designs Organic, Plate and Snowflake, the section height was $H=$ $100 \mathrm{~mm}$. The fin design Eco was modeled with heights $H=50 \mathrm{~mm}, 100 \mathrm{~mm}$ and $200 \mathrm{~mm}$ to additionally investigate the influence of height. 


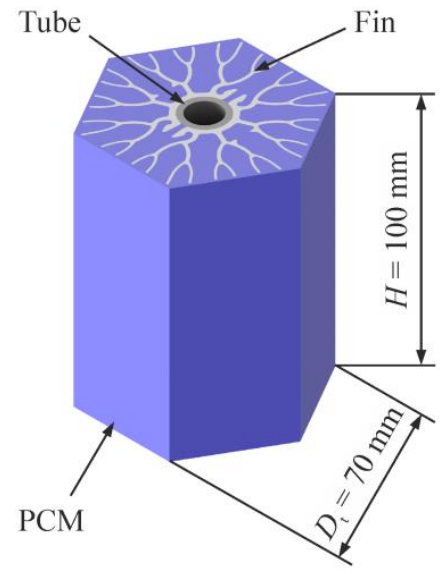

a) Axial-70 Organic

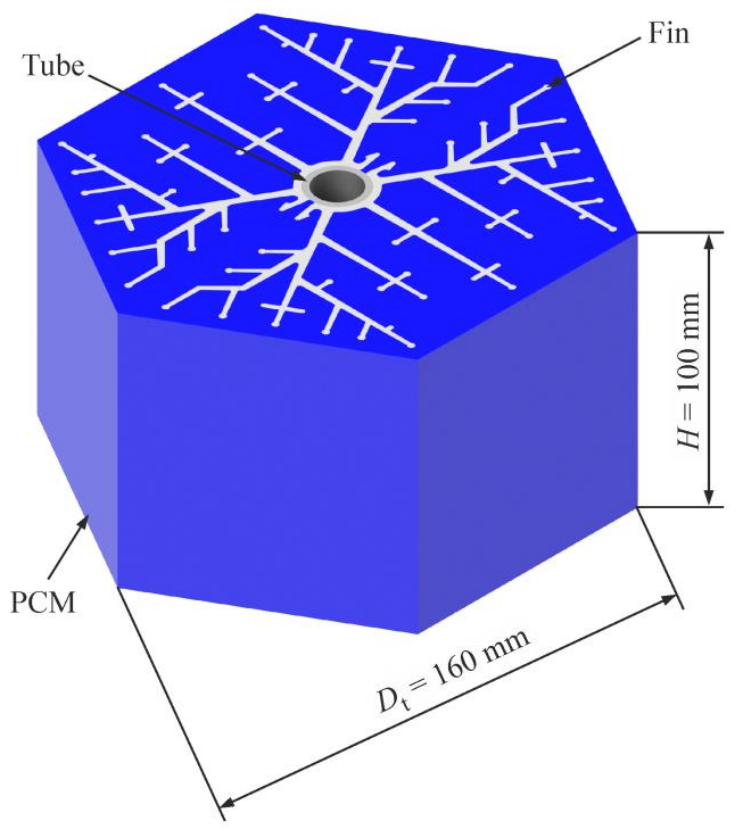

c) Axial-160 Snowflake

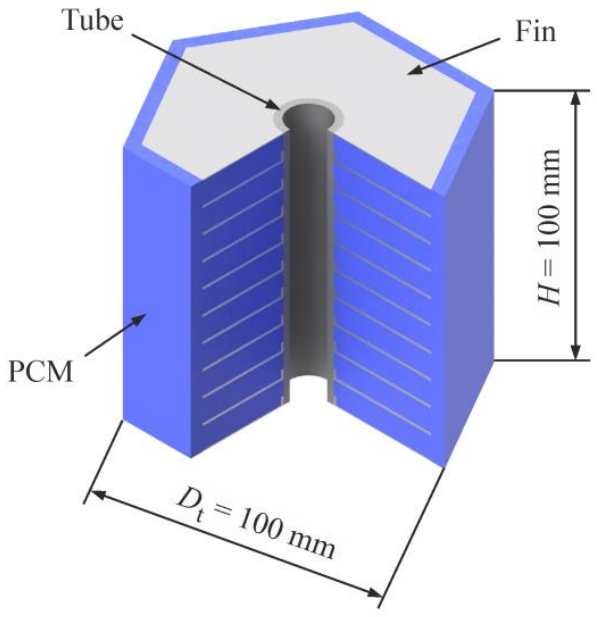

b) Radial-100 Plate

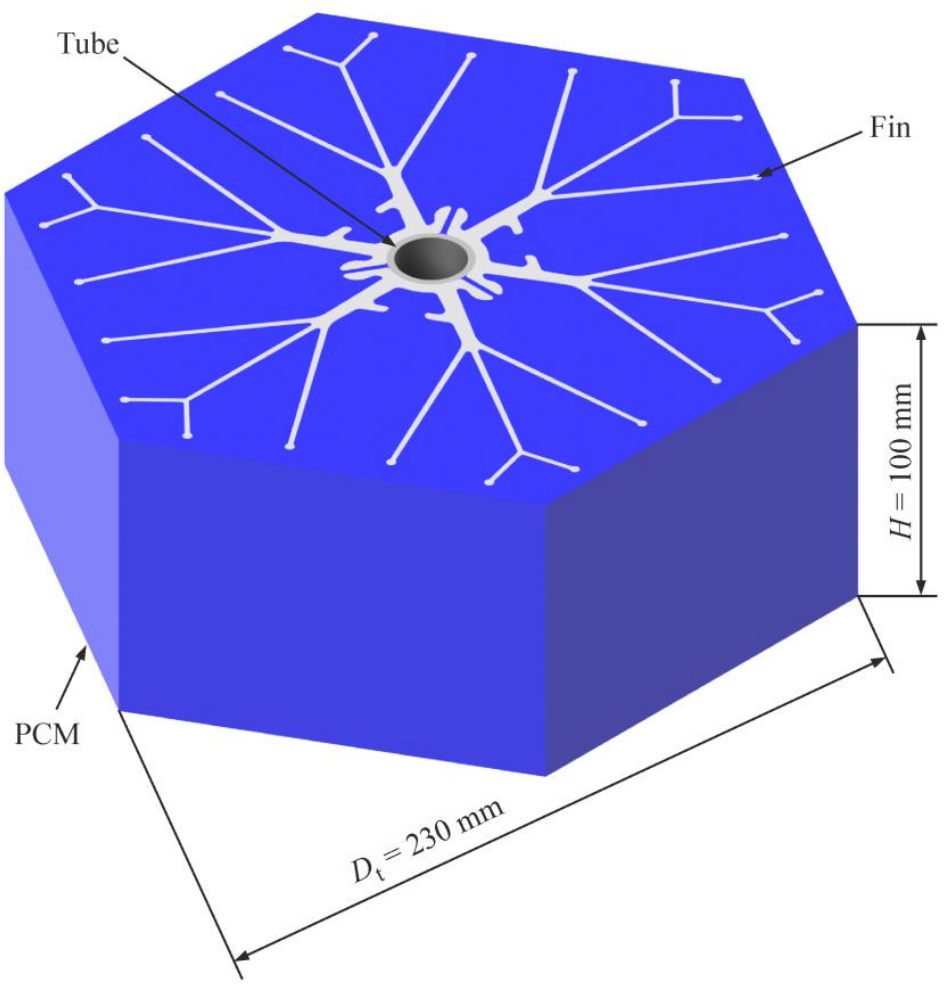

d) Axial-230 Eco

Figure 1: Geometries of the four investigated fin designs: a) Axial fin Organic with $D_{\mathrm{t}}=70 \mathrm{~mm}$ tube distance and $17.9 \%$ fin to PCM fraction, b) Radial fin Plate with $D_{\mathrm{t}}=100 \mathrm{~mm}$ tube distance and $8.2 \%$ fin to PCM fraction c) Axial fin Snowflake with $D_{\mathrm{t}}=160 \mathrm{~mm}$ tube distance and $14.3 \%$ fin to PCM fraction and d) Axial fin Eco with $D_{\mathrm{t}}=230 \mathrm{~mm}$ tube distance and $9.0 \%$ fin to PCM fraction.

\section{Numerical modeling}

To investigate the heat transfer process of natural convection, a section of a single tube of a shell-and-tube PCM storage system was analyzed. The natural convection model was restricted to small dimensions, because the small cell sizes and time steps required to solve the heat and mass transfer process lead to high computational effort. The model was developed with the commercial software package ANSYS ${ }^{\odot}$ Fluent 16, where the incompressible Navier-Stokes equations with Boussinesq-approximation in the buoyancy term of the momentum equation, the energy equation and a source term enthalpy method were solved using a finite volume unstructured grid. With the Boussinesq approximation, a constant density was assumed, and the buoyancy term was linearized to directly depend on temperature. This also means that neither was there a density change due to phase change, nor did volume expansion occur. The remaining properties were also assumed as constants. However, these effects are minor and the validity of the Boussinesq approximation for the present model was shown by Vogel and Thess [30] in 
comparison to a more sophisticated model with volume expansion.

A similar modeling approach as in this study was validated by Vogel et al. [21] using temperature data of experiments of a lab-scale flat plate storage system. Another similar modeling approach was validated in more detail by Vogel and Thess [30] using phase state, velocity and temperature data of the benchmark experiment by Vogel and Bauer [31]. In this work, we rely on using the same modeling approach as in the previously validated models and only change the geometry of the storage system.

\subsection{Model simplifications}

The following simplifications were used: 1) the flow in the liquid phase of the PCM is incompressible and Newtonian, 2) the sharp interface between the solid and liquid phase of the pure PCM or eutectic mixture of multiple PCMs is represented by a narrow so-called mushy region, where the material is neither solid nor liquid but a mixture of both phases, 3) the solid phase does not move - no sinking of the solid phase or close contact melting occurs, 4) natural convection in the PCM is laminar, 5) radiation and viscous dissipation are negligible, 6) the Boussinesq approximation is valid in this case and density change (or volume expansion) of the PCM during melting is negligible, and 8) constant thermophysical properties of the PCM are sufficiently accurate.

\subsection{Governing equations}

The conservation equations of mass, momentum and energy were solved with the Boussinesq approximation [32]: The continuity equation with constant density is

$\nabla \cdot \mathbf{u}=0$

where $\mathbf{u}=(u, v, w)^{\top}$ is the flow velocity in the $x, y$ and $z$ direction, respectively. The momentum equation with buoyancy term $\mathbf{F}_{\mathrm{b}}$ and a momentum source term $\mathbf{S}_{\mathbf{u}}$ is

$\rho \frac{\partial \mathbf{u}}{\partial t}+\rho(\mathbf{u} \cdot \nabla) \mathbf{u}=\mu \Delta \mathbf{u}-\nabla p+\mathbf{F}_{\mathrm{b}}+\mathbf{S}_{\mathbf{u}}$

where $\rho$ is the density, $p$ is the pressure and $\mu$ is the dynamic viscosity. Here, $\Delta$ is the Laplace operator. With the Boussinesq approximation, the Buoyancy term is

$\mathbf{F}_{\mathrm{b}}=g \rho \beta\left(T-T_{\mathrm{m}}\right) \hat{\mathbf{e}}_{\mathbf{z}}$.

The buoyancy depends on the thermal expansion coefficient $\beta$ and a temperature difference to a reference temperature, at which the density was specified. In this case the reference temperature is the melting temperature $T_{\mathrm{m}}$.

The energy equation for the specific enthalpy $h$ with an enthalpy source term $S_{h}$ is

$\rho \frac{\partial h}{\partial t}+\rho \nabla(\mathbf{u} h)-k \Delta T=S_{h}$.

The energy equation is transformed with the enthalpyporosity method, which has been developed and discussed by Voller and Prakash [33], Brent et al. [34] as well as Voller and Swaminathan [35]. The central idea of the method is to write the enthalpy $h$ as the sum of the sensible enthalpy $h_{\text {sens }}$ and the latent enthalpy $h_{\text {lat }}$ : $h=h_{\text {sens }}+h_{\text {lat }}$.

The sensible enthalpy is

$h_{\text {sens }}(T)=\int_{T_{\text {ref }}}^{T} c_{p} d T^{\prime}$

and the latent enthalpy is the product of the latent heat of fusion $L$ and the liquid phase fraction $f_{1}$ :

$h_{\text {lat }}=L f_{1}$.

The liquid phase fraction is in general defined by the temperature $T$ in relation to the solidus temperature $T_{\mathrm{s}}$ and the liquidus temperature $T_{1}$ :

$f_{\mathrm{l}}=\left\{\begin{array}{cc}0, & T \leq T_{\mathrm{s}} \\ 0 \ldots 1, & T_{\mathrm{s}}<T<T_{1}, \\ 1, & T \geq T_{\mathrm{l}}\end{array}\right.$

In the so-called mushy region, $0<f_{1}<1$, the material is neither solid nor liquid, but in a state of melting or solidification. In this region, a relationship between liquid phase fraction and temperature has to be defined. ANSYS ${ }^{\circledR}$ Fluent offers two variations of the enthalpy-porosity technique: the melting point model [33] and the melting range model [35]. Although both methods are feasible, we obtained better results with the melting point model in a previous study [30] and therefore continued to use this model.

In the melting point model [33], a linear relationship over a small temperature range of $2 \xi$ between $T_{\mathrm{s}}=T_{\mathrm{m}}-\xi$ and $T_{1}=T_{\mathrm{m}}+\xi$ is introduced and the liquid phase fraction is then defined as:

$f_{\mathrm{l}}=\left\{\begin{array}{cc}0, & T \leq T_{\mathrm{m}}-\xi \\ \frac{T-\left(T_{\mathrm{m}}-\xi\right)}{2 \xi}, & T_{\mathrm{m}}-\xi<T<T_{\mathrm{m}}+\xi, \\ 1, & T \geq T_{\mathrm{m}}+\xi\end{array}\right.$

After introducing equation (6) in equation (5), dropping the subscript "sens" and defining the energy equation source term as

$S_{h}=L\left(\frac{\partial}{\partial t}\left(\rho f_{\mathrm{l}}\right)+\nabla \cdot\left(\rho \mathbf{u} f_{\mathrm{l}}\right)\right)$,

the original form of the energy equation (5) is obtained with the latent enthalpy being expressed in the source term:

$$
\begin{aligned}
\frac{\partial}{\partial t}(\rho h)+\nabla \cdot(\rho \mathbf{u} h) & -\nabla \cdot(k \nabla T) \\
= & L\left(\frac{\partial}{\partial t}\left(\rho f_{1}\right)+\nabla \cdot\left(\rho \mathbf{u} f_{1}\right)\right)
\end{aligned}
$$

To modify the velocities in the mushy region and in the solid [33], another source term is introduced into the momentum equation (3),

$\mathbf{S}_{\mathbf{u}}=-B\left(f_{\mathrm{l}}\right) \mathbf{u}$,

where a parameter $B\left(f_{\mathrm{l}}\right)$, which depends on the liquid phase fraction, is multiplied with the velocity vector. This parameter has to be zero in the liquid phase to allow for free motion. When the parameter $B\left(f_{1}\right)$ takes large values in the solid phase, the velocities are forced to near zero values in the linear system 
of equations of an implicit method [34]. While different functions fulfil this requirement, most often the CarmanKozeny equation, which is derived from the D'Arcy law for fluid flow in porous media [36], is used in a modified form [32]:

$B\left(f_{\mathrm{l}}\right)=C \frac{\left(1-f_{\mathrm{l}}\right)^{2}}{f_{\mathrm{l}}{ }^{3}+q}$.

The original Carman-Kozeny equation would yield infinity if the liquid phase fraction approached zero. To limit $B\left(f_{1}\right)$ to numerically applicable finite values, a constant value $q$ is additionally added in the denominator. In ANSYS Fluent, the value is fixed to $q=10^{-3}$. The parameter $C$ is called the mushy region or mushy zone constant and is a model constant, which replaces the physical properties in the Carman-Kozeny equation. This constant has to be adjusted to the problem, because it will influence the morphology of the mushy region, as discussed by Voller and Prakash [33]. Investigations on the influence of the value $C$ were described by Shmueli et al. [37]. In our study, a standard value of $10^{6}$ was used. We found that using a melting point material, the solution is rather insensitive to this parameter compared to a melting range material. With a melting point material, the mushy zone is expected to be narrow, approximately as wide as a computational cell, and to exist only due to the discretization error.

\subsection{Material properties, initial conditions and boundary conditions}

The materials used in these design concepts are discussed in the papers detailing the design and integration of these fins. As discussed in section 2, the Organic fin is discussed by Johnson et al. [13,27], the Plate fin by Laing et al. [4,28], the Snowflake fin by Laing et al. [4] and the Eco design by Hübner et al. [29]. In addition, Johnson et al. [38] discuss methods for attaching fins to tubes in PCM storages and therein discuss the material choices for finned tubes.

Phase change materials suitable for mid-range temperature industrial applications are, for example, nitrate salts as discussed by Bauer et al. [39] and Bauer et al. [40]. Of the nitrate salts, sodium nitrate has a melting point suitable for many applications. Furthermore, it is inexpensive and available, can be easily handled and has a good cyclic stability. The properties and characterization of sodium nitrate are discussed by Bauer et al. [40] and Bauer and Laing [41]. The material properties for this PCM as well as the fin material aluminum 6060 and the tube material steel 1.4571, which are used in this study, are given in Table 2.
Table 2: Thermophysical material properties. PCM material properties density, heat capacity and thermal conductivity are mean values of solid and liquid state near the melting temperature [40]. The dynamic viscosity is given in the liquid state at temperature $311^{\circ} \mathrm{C}$ [42].

\begin{tabular}{lcccc}
\hline Material property & Unit & $\begin{array}{c}\mathrm{PCM} \\
\mathrm{NaNO}_{3}\end{array}$ & $\begin{array}{c}\text { Fin } \\
\mathrm{Al} 6060\end{array}$ & $\begin{array}{c}\text { Tube } \\
\text { St } 1.4571\end{array}$ \\
\hline Density $\rho$ & $\mathrm{kg} / \mathrm{m}^{-3}$ & 2010.5 & 2700 & 7800 \\
Heat capacity $c_{p}$ & $\mathrm{~J} /(\mathrm{kg} \mathrm{K})$ & 1655 & 1020 & 480 \\
Therm. cond. $k$ & $\mathrm{~W} /(\mathrm{m} \mathrm{K})$ & 0.56 & 210 & 16.3 \\
Melting point $T_{\mathrm{m}}$ & ${ }^{\circ} \mathrm{C}$ & 306 & - & - \\
Latent heat $L$ & $\mathrm{~kJ} / \mathrm{kg}$ & 178 & - & - \\
Therm. exp. co. $\beta$ & $1 / \mathrm{K}$ & $3.5 \cdot 10^{-4}$ & - & - \\
Dyn. viscosity $\mu$ & $\mathrm{Pa} \mathrm{s}$ & $2.9 \cdot 10^{-3}$ & - & - \\
\hline
\end{tabular}

Most of the properties of $\mathrm{NaNO}_{3}$ are given by Bauer et al. [40] in a temperature dependent form. However, the density, heat capacity and thermal conductivity used in this study are the mean values of the solid and liquid value near the melting point. The thermal expansion coefficient is calculated from the density gradient in the liquid phase near the melting temperature $T_{\mathrm{m}}$ :

$\beta=-\left.\frac{1}{\rho} \frac{\partial \rho_{\mathrm{l}}}{\partial T}\right|_{T_{\mathrm{m}}}$.

The dynamic viscosity is given by Janz [42], from which we selected the value at temperature $311^{\circ} \mathrm{C}$.

A melting process is defined with an initially solid material at an initial temperature $\left(T_{0}=T_{\mathrm{m}}=306^{\circ} \mathrm{C}\right)$ and a temperature boundary condition $\left(T_{\mathrm{w}}=T_{\mathrm{m}}+10 \mathrm{~K}=316^{\circ} \mathrm{C}\right)$ set at the inner tube wall. All other sides of the domain are adiabatic.

The bottom of the domain is modeled as a no-slip wall. The top of the domain is modeled with a slip boundary condition to allow fluid motion in the liquid phase of the PCM, similar to a free surface. The sides are also modeled with a slip boundary condition, because of the symmetry to the neighboring finned tubes.

\subsection{Discretization}

The governing equations were discretized with a pressurebased finite volume method [43] and implicit time integration with ANSYS ${ }^{\odot}$ Fluent 16 [26]. The segregated solver was used with the PISO method for pressure-velocity-coupling [44]. The second order derivatives in the diffusive terms were approximated by second order central differences, the first order derivatives in the convective terms with a second order upwind scheme. The interpolation of pressure values at the cell faces was done with the PRESTO! scheme [43]. The resulting linear systems were solved with an iterative method with algebraic multigrid acceleration [43].

The three-dimensional geometries of the four fin designs were discretized with ANSYS ${ }^{\odot}$ meshing [26]. The resulting computational grids are shown for each of the geometries in Figure 2. 


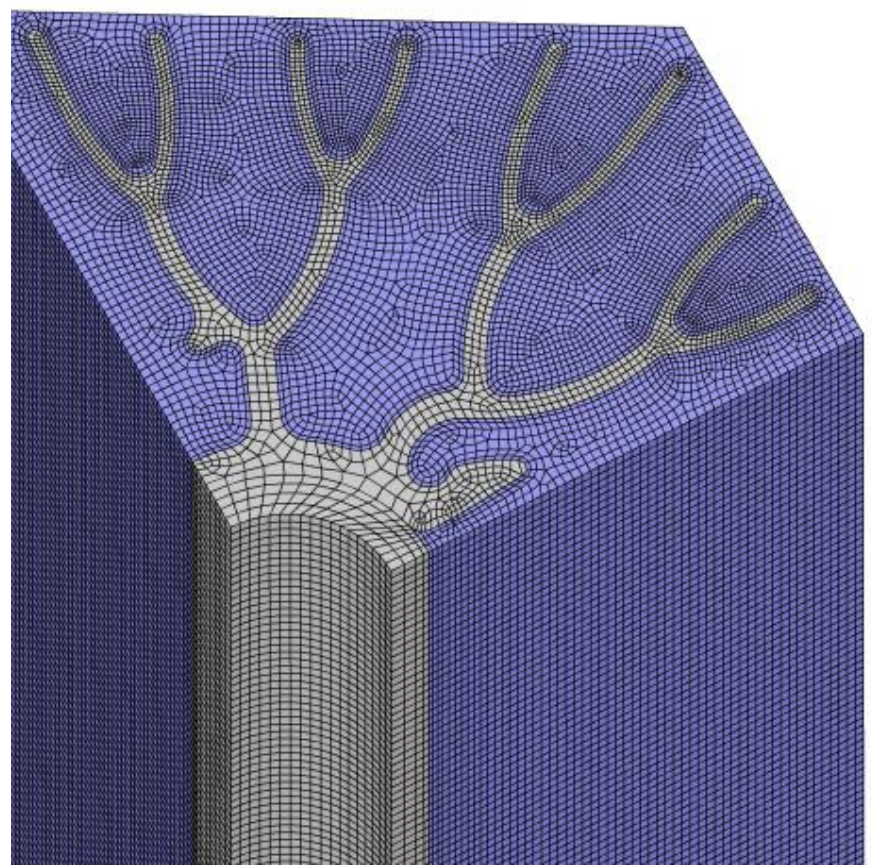

a) Axial-70 Organic

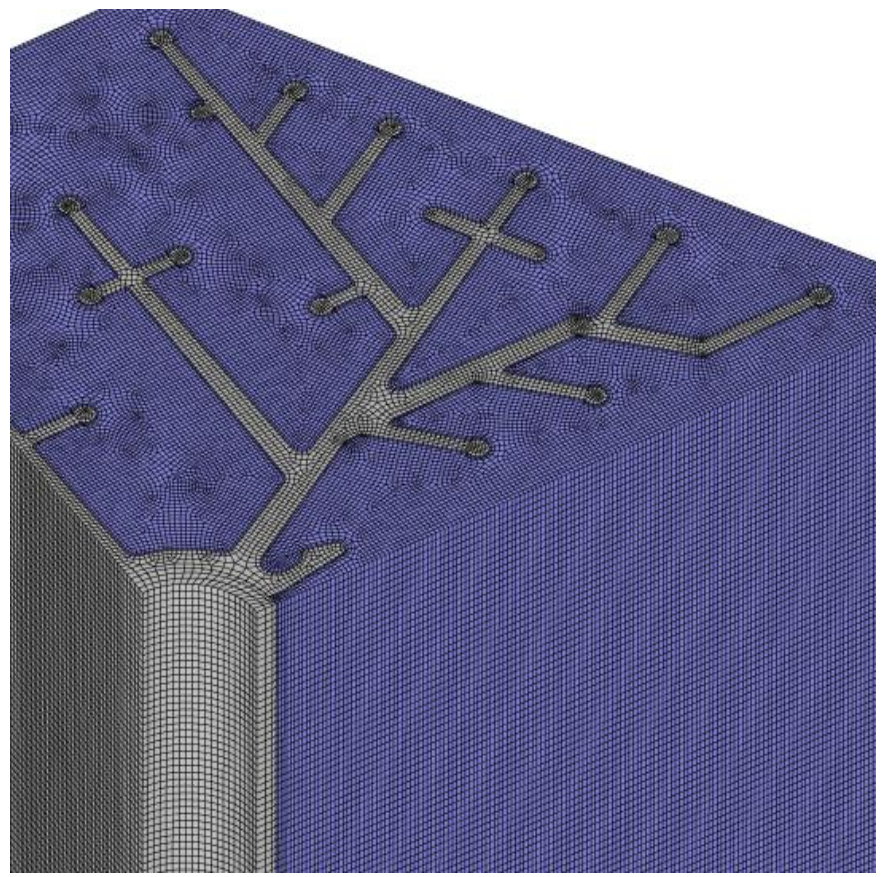

c) Axial-160 Snowflake

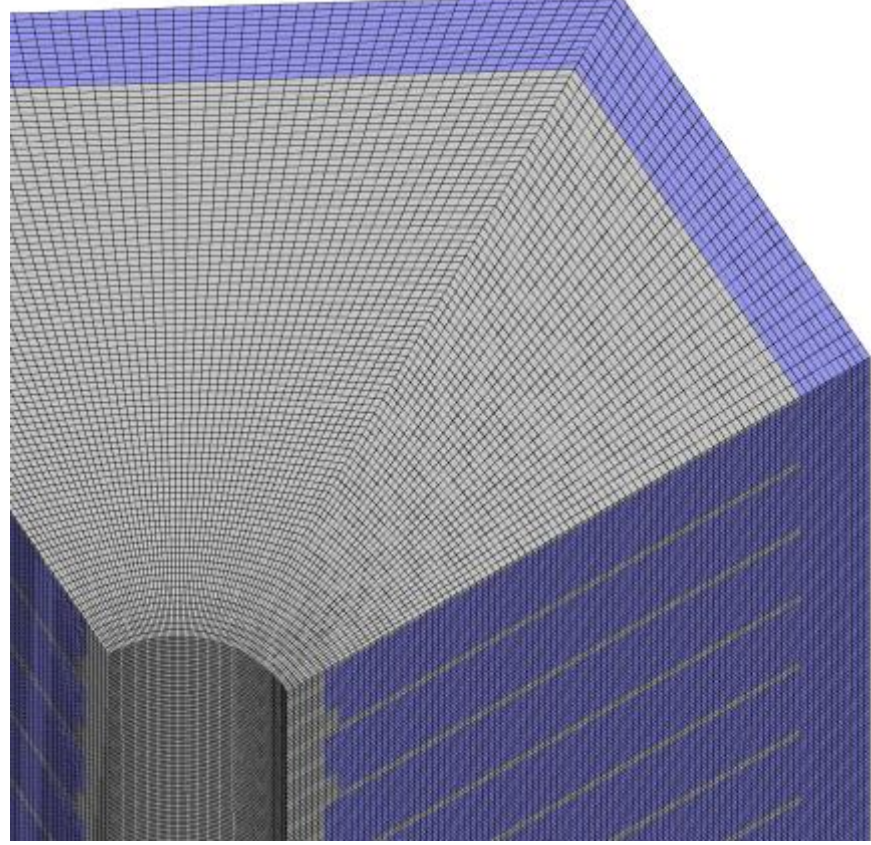

b) Radial-100 Plate

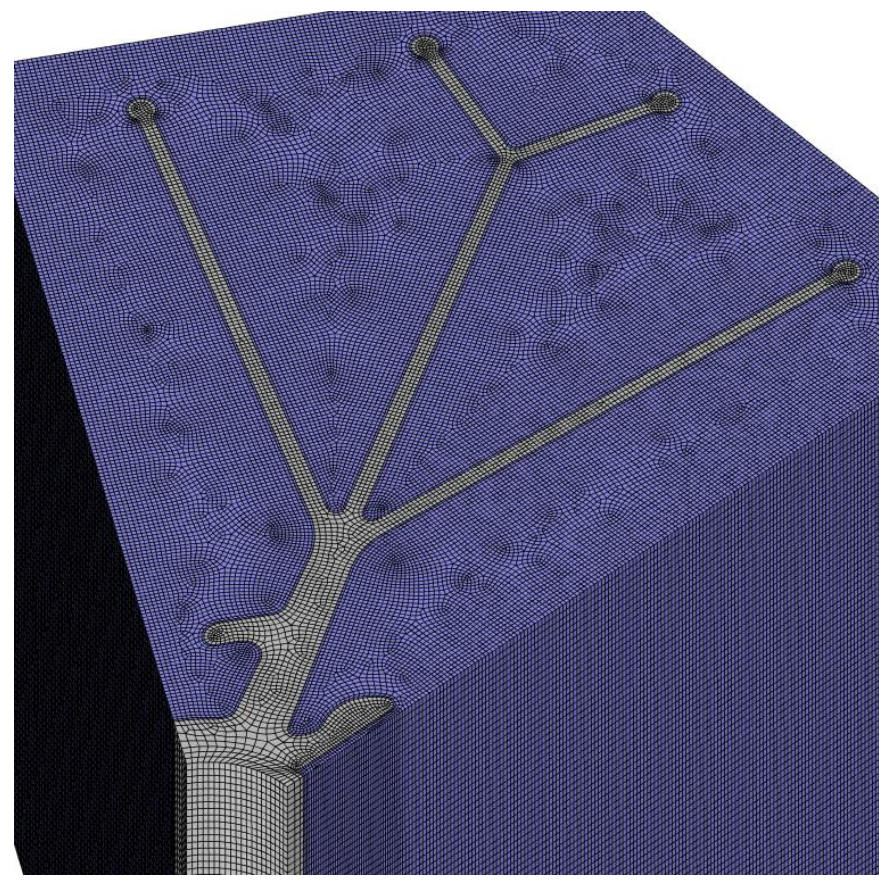

d) Axial-230 Eco

Figure 2: Computational grids of the four investigated fin designs a) Organic, b) Plate, c) Snowflake and d) Eco. Solid materials, which are either the steel tube or the aluminum fin, are shown in gray and the phase change material is shown in blue. Both the differences in geometries as well as the grid structures are shown.

The radial plate fin could be meshed with a structured, radially swept mesh using only hexahedron cells. For the axial fins, a hybrid structured/unstructured mesh with mixed prism and hexahedron cells was used. The tube thereby consists of only structured hexahedrons, the fin consists of unstructured hexahedrons and prisms. The PCM has a narrow inflation layer to improve resolution in the boundary layer at the wall and hexahedron and prism cells outside the inflation layer. The cell sizes in the radial direction vary between a minimum and maximum value with a transition rate of 1.3 and the size in the axial direction is fixed. The number of control volumes, their sizes in the radial and axial directions, and the time step length are given in Table 3 for all of the meshes. 
Table 3: Discretization properties of the four fin designs with height $H=100 \mathrm{~mm}$.

\begin{tabular}{lllll}
\hline \multirow{2}{*}{ Mesh property } & $\begin{array}{l}\text { Axial-70 } \\
\text { Organic }\end{array}$ & $\begin{array}{l}\text { Radial-100 } \\
\text { Plate }\end{array}$ & $\begin{array}{l}\text { Axial-160 } \\
\text { Snowflake }\end{array}$ & $\begin{array}{l}\text { Axial-230 } \\
\text { Eco }\end{array}$ \\
\hline Number of control volumes & 827,400 & $1,488,000$ & $2,482,722$ & $3,133,053$ \\
Cell size in radial direction / $\mathrm{mm}$ & $0.25 \ldots 0.5$ & 0.5 & $0.25 \ldots 0.5$ & $0.25 \ldots 0.5$ \\
Cell size in axial direction / $\mathrm{mm}$ & 1 & 0.5 & 1 & 1 \\
Time step / s & 0.1 & 0.05 & 0.1 & 0.1 \\
\hline
\end{tabular}

In every time step, iterations were performed until all of the convergence criteria were met. The scaled residual convergence thresholds were set to $10^{-3}$ for both the continuity and the momentum equations and $10^{-9}$ for the energy equation.

\section{Results}

To present our results, we first visualize the melting process to show how it depends on the liquid phase fraction and how it develops differently for each fin design. Secondly, we present quantitative results of interest, which are the heat flux, liquid phase fraction, convective enhancement factor and the maximum velocity magnitude. Finally, a dimensional analysis is performed, the results are presented in non-dimensional form and a correlation function is derived for the mean convective enhancement factor. At the end of the results section, we have a clear understanding of the impact of natural convection on the melting process and, due to the dimensional analysis, we are able to extrapolate the results to other similar fin designs, thereby improving and simplifying the design process for LTES.

\subsection{Visualization of the melting process}

The melting process is governed by three primary variables: the temperature, the liquid phase fraction and the velocity in the liquid phase due to natural convection. Moreover, the results are three-dimensional and transient with each simulation having its own time-scale. This results in a large set of data that has to be reduced for analysis. We created plots for each fin design at three different liquid phase fractions to illustrate the melting process and compare the different fin designs. These liquid phase fractions are reached at different times for each fin design. The results are shown in Figure 3 for a liquid phase fraction $f_{1} \approx 0.25$, in Figure 4 for a liquid phase fraction of $f_{1} \approx 0.5$ and in Figure 5 for a liquid phase fraction of $f_{1} \approx 0.75$. 


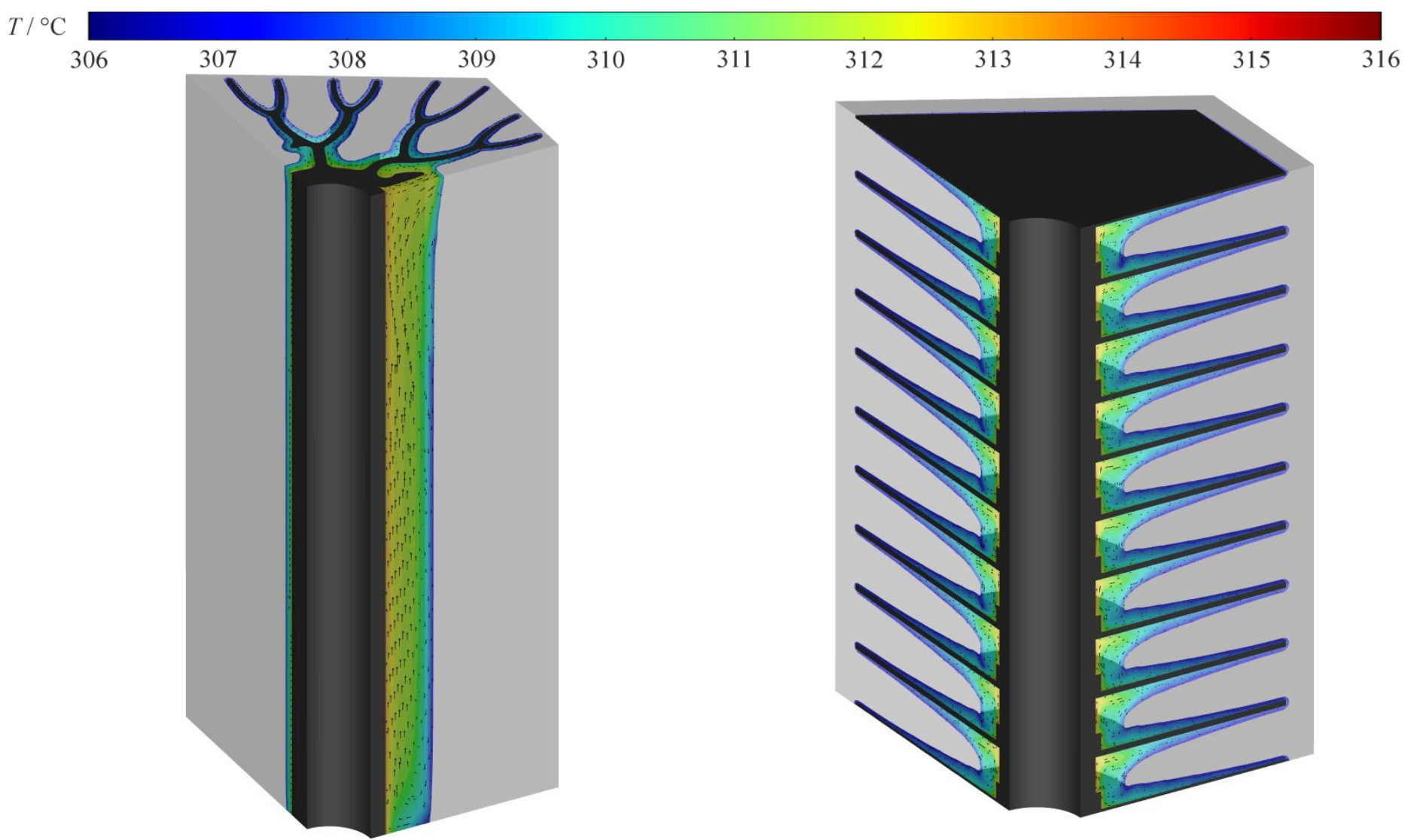

a) Axial-70 Organic $\left(t=200 \mathrm{~s}, f_{\mathrm{l}}=0.24\right)$

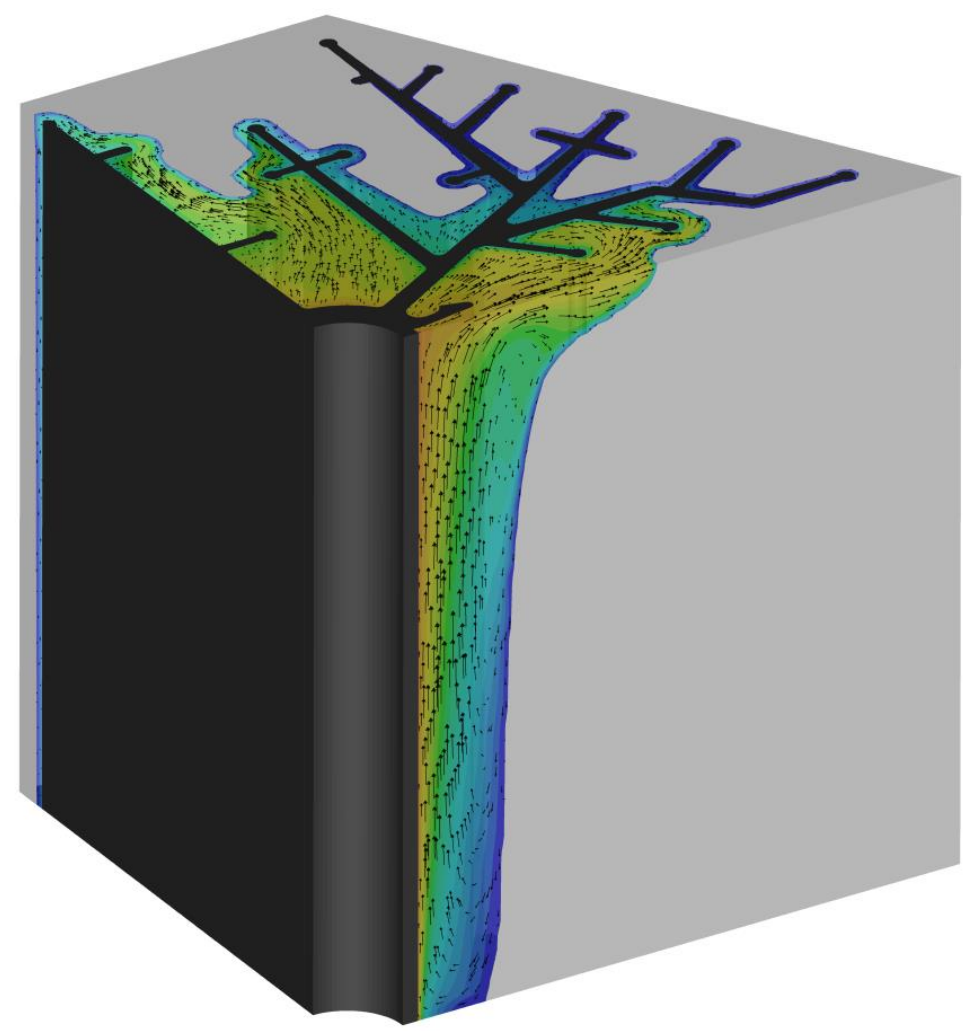

b) Radial-100 Plate ( $\left.t=700 \mathrm{~s}, f_{\mathrm{l}}=0.24\right)$

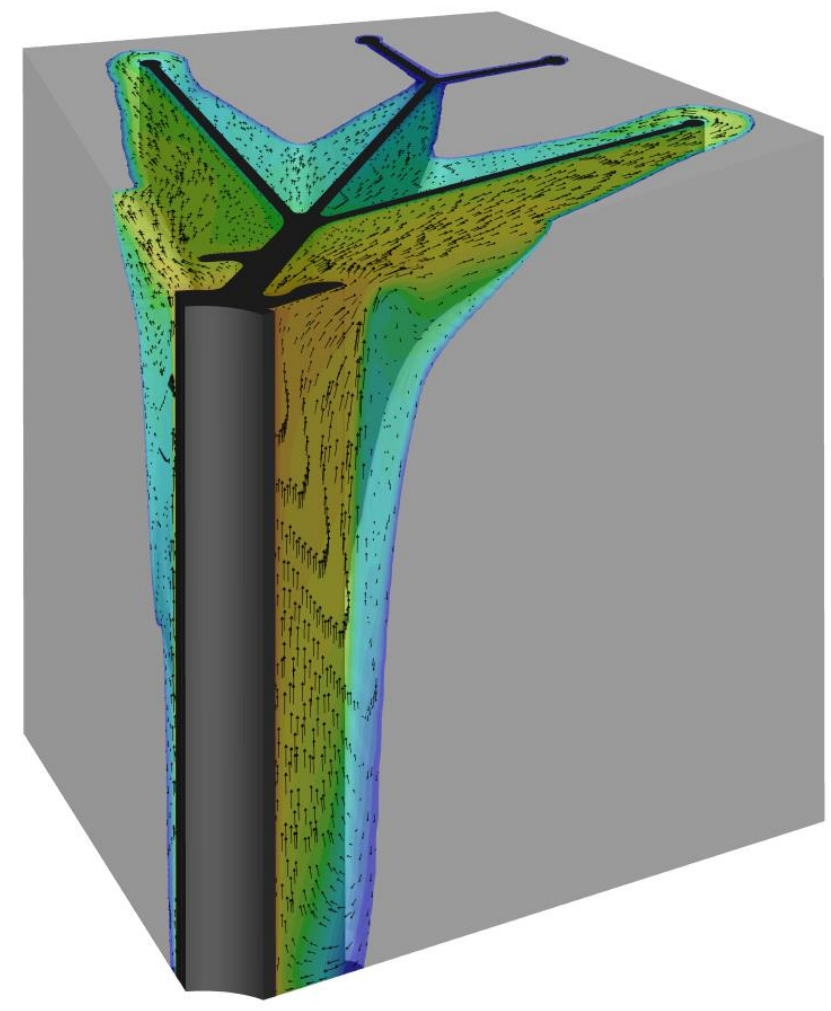

c) Axial-160 Snowflake $\left(t=1400 \mathrm{~s}, f_{\mathrm{l}}=0.24\right)$

d) Axial-230 Eco $\left(t=2700 \mathrm{~s}, f_{\mathrm{l}}=0.25\right)$

Figure 3: Simulation results visualized at times corresponding to $f_{1} \approx 0.25$ and correspondingly different times t, allowing for a comparison of the four designs at the same degree of melting. The solid phase boundary is depicted by gray surfaces, temperatures in the liquid phase at the outer boundaries by transparent contours and velocities in the liquid phase at the outer boundaries by scaled vectors. 


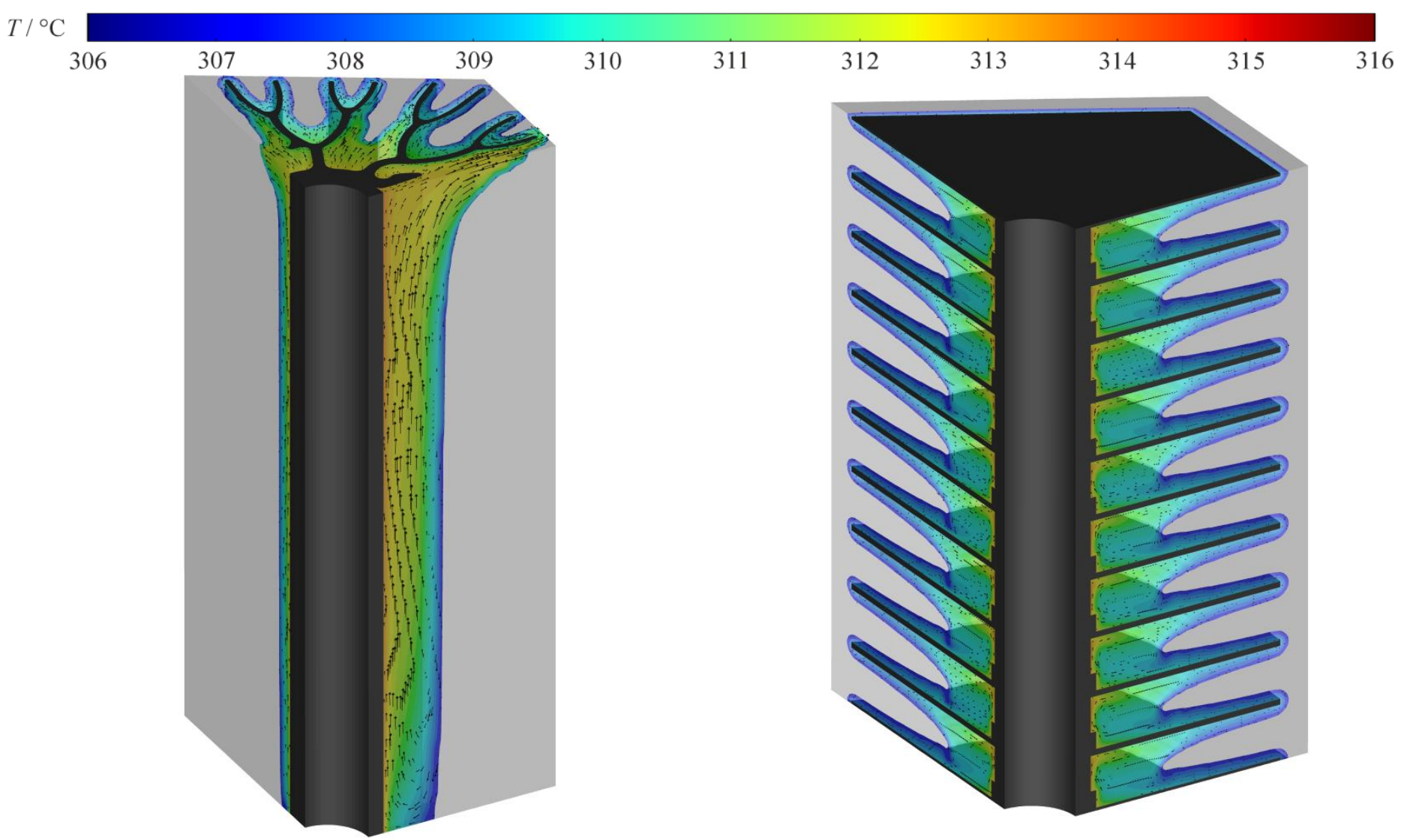

a) Axial-70 Organic $\left(t=500 \mathrm{~s}, f_{\mathrm{l}}=0.52\right)$

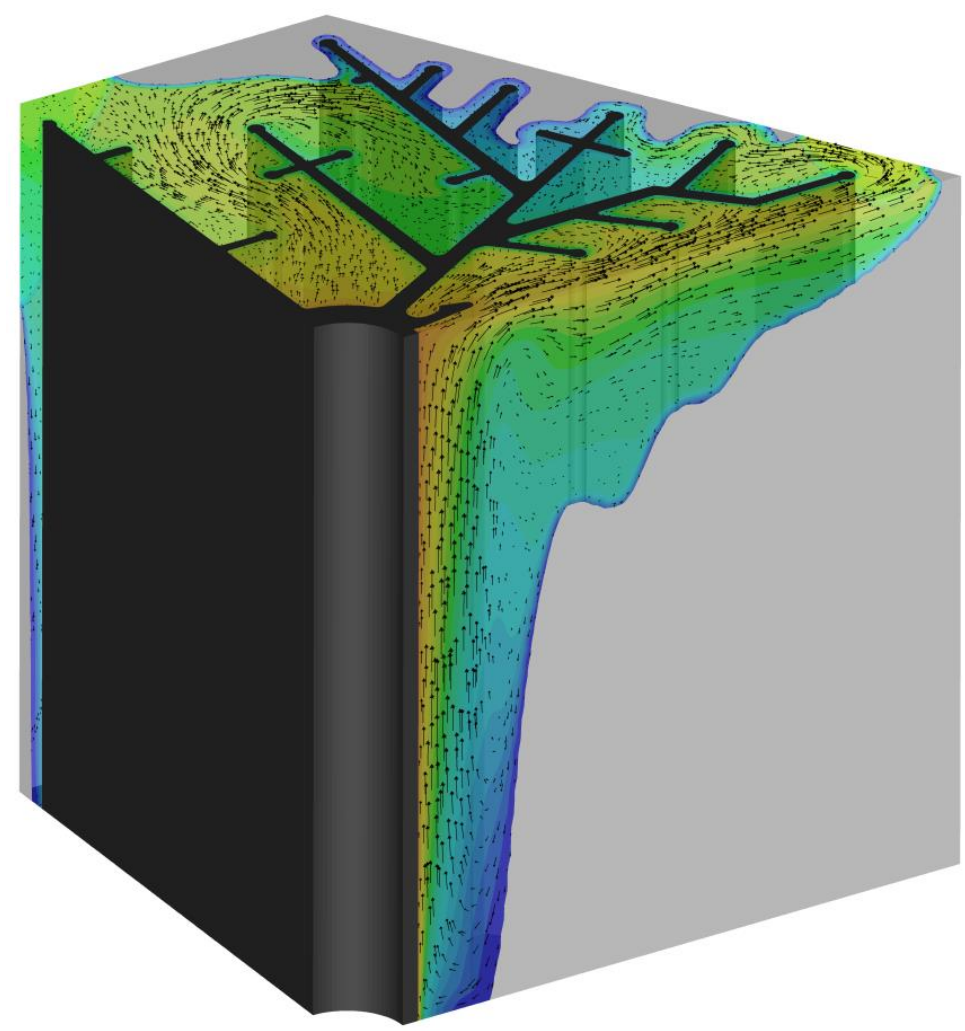

b) Radial-100 Plate $\left(t=1600 \mathrm{~s}, f_{\mathrm{l}}=0.49\right)$

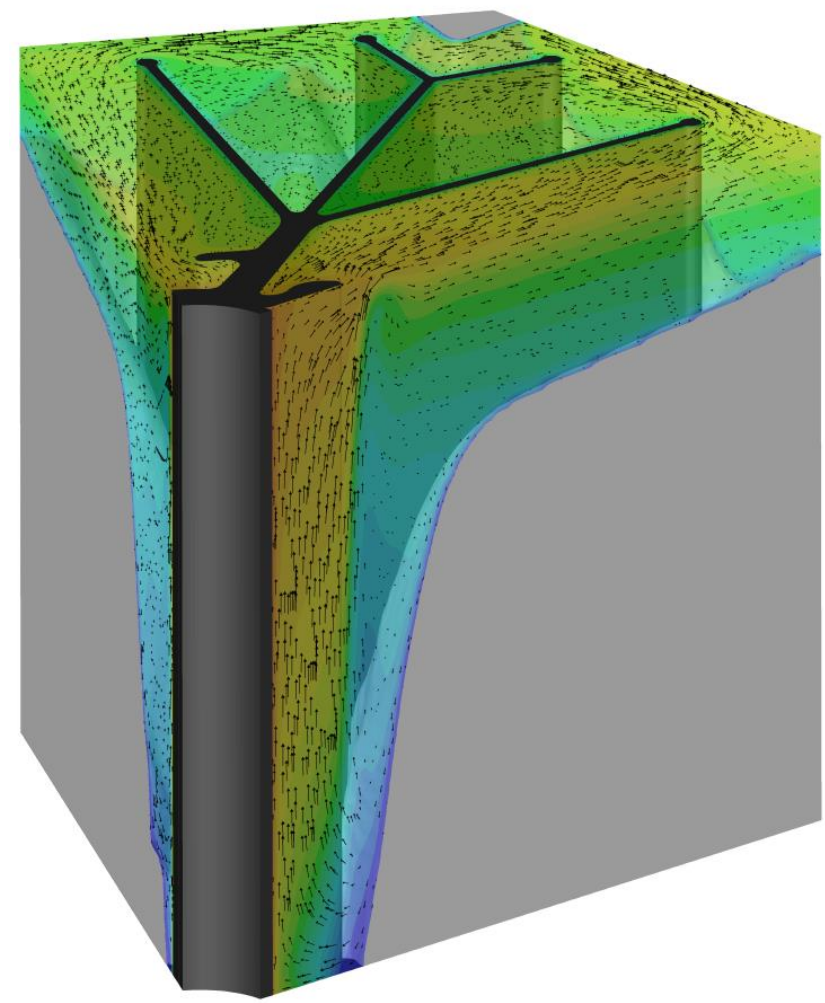

c) Axial-160 Snowflake $\left(t=3100 \mathrm{~s}, f_{\mathrm{l}}=0.50\right)$

d) Axial-230 Eco $\left(t=5700 \mathrm{~s}, f_{\mathrm{l}}=0.50\right)$

Figure 4: Simulation results visualized at times corresponding to $f_{1} \approx 0.50$. The solid phase boundary is depicted by gray surfaces, temperatures in the liquid phase at the outer boundaries by transparent contours and velocities in the liquid phase at the outer boundaries by scaled vectors. 


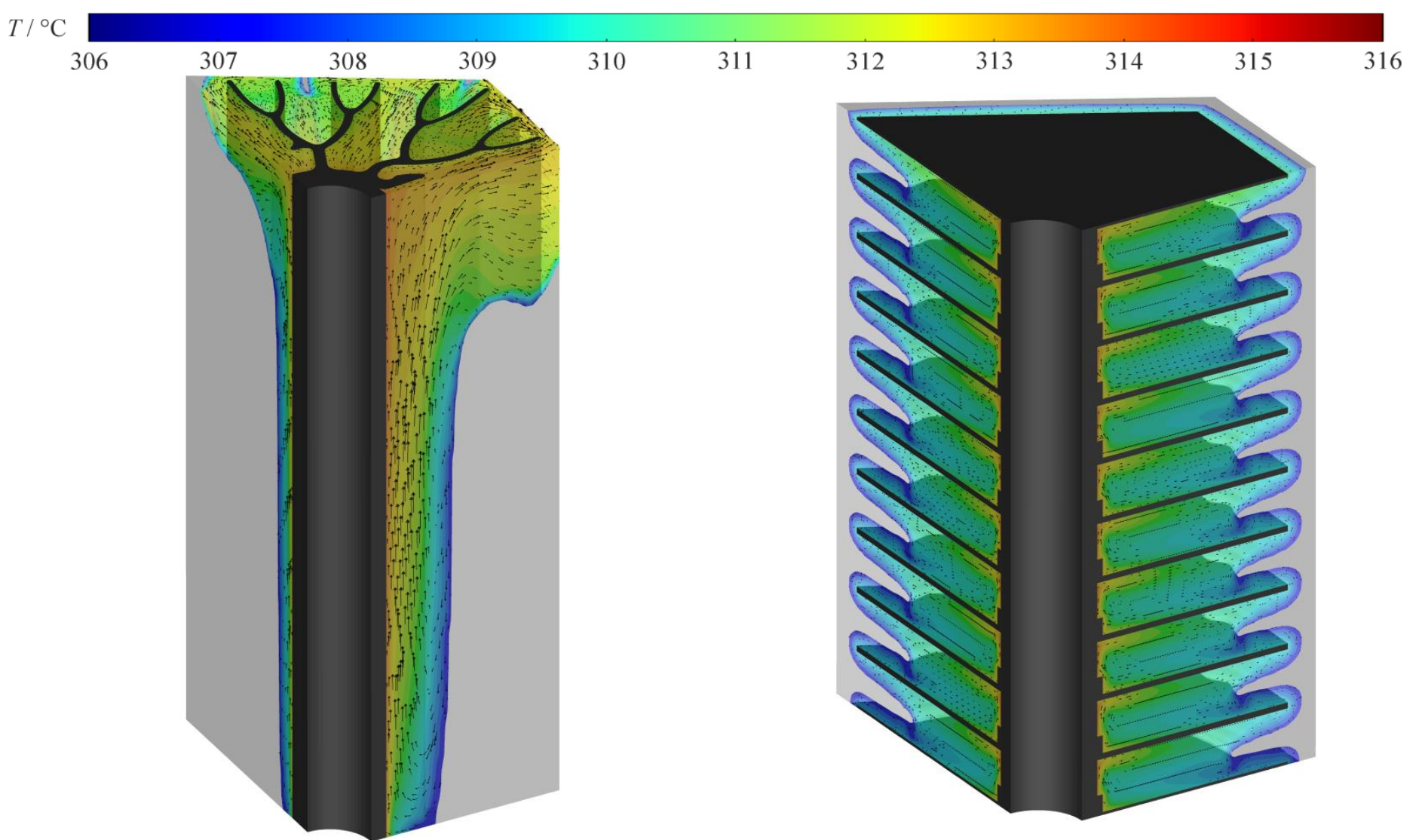

a) Axial-70 Organic $\left(t=800 \mathrm{~s}, f_{\mathrm{l}}=0.74\right)$

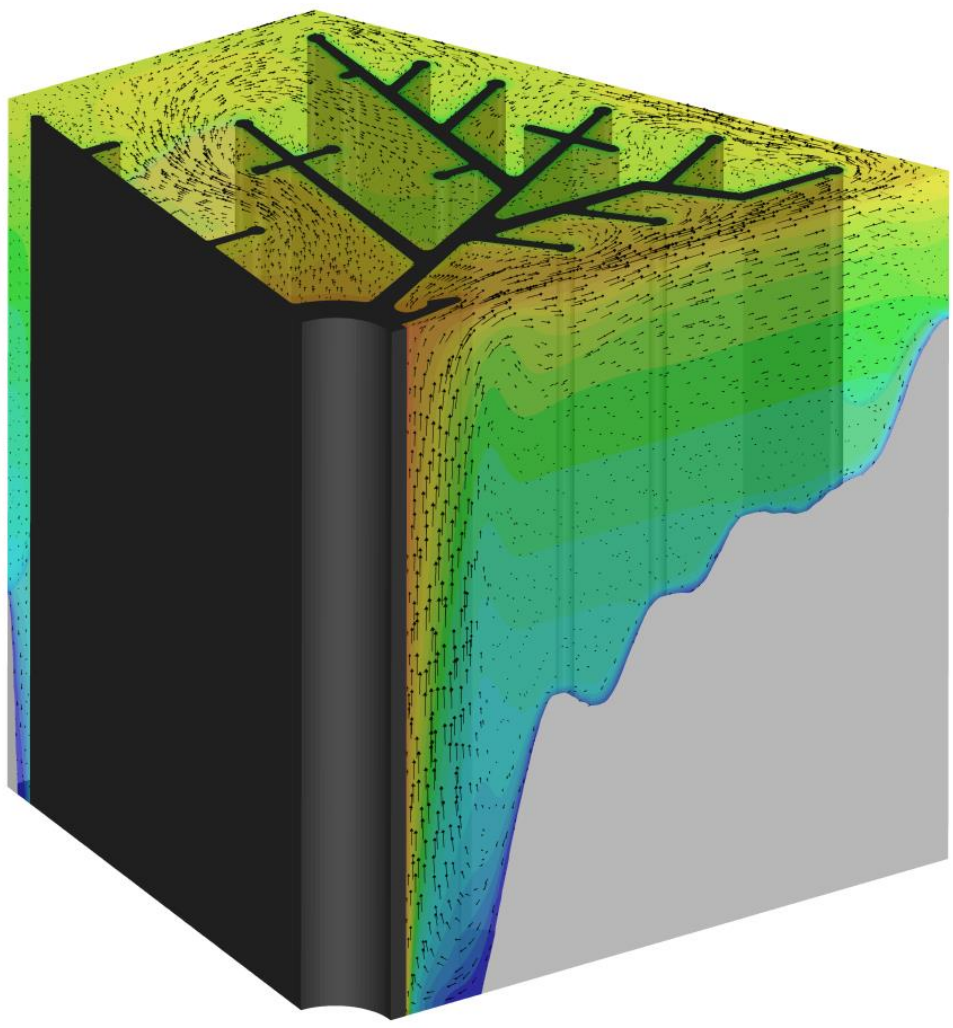

b) Radial-100 Plate $\left(t=2700 \mathrm{~s}, f_{\mathrm{l}}=0.75\right)$

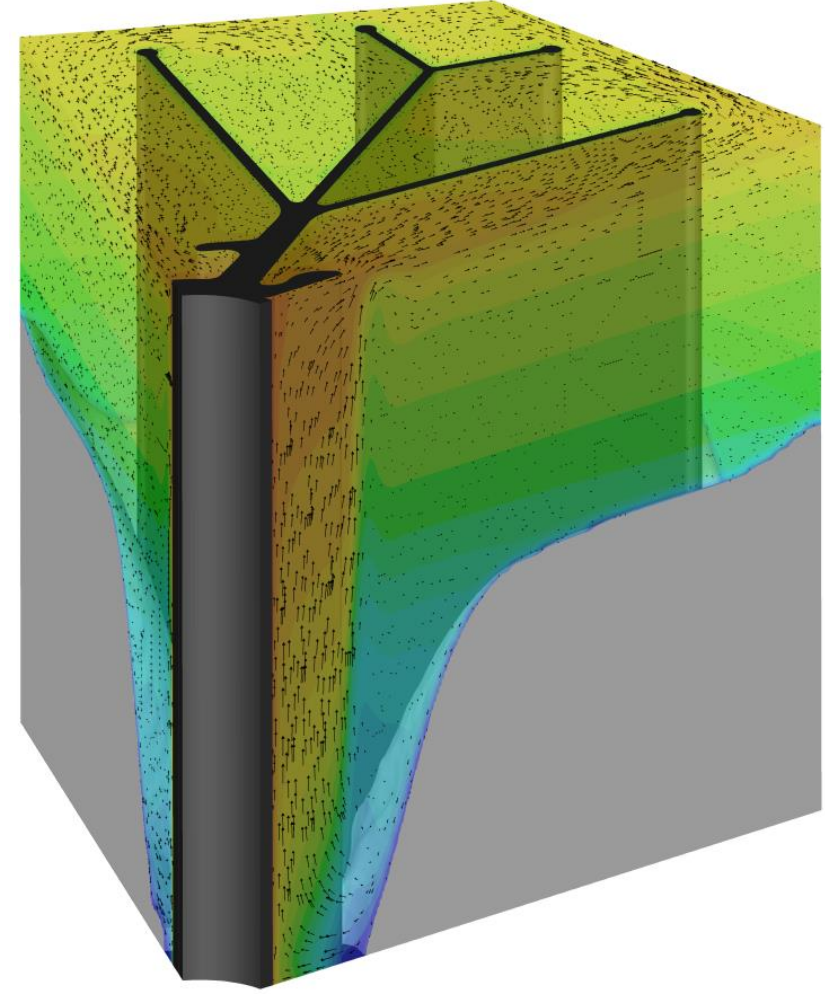

c) Axial-160 Snowflake $\left(t=5000 \mathrm{~s}, f_{\mathrm{l}}=0.75\right)$

d) Axial-230 Eco $\left(t=9000 \mathrm{~s}, f_{\mathrm{l}}=0.75\right)$

Figure 5: Simulation results visualized at times corresponding to $f_{1} \approx 0.75$. The solid phase boundary is depicted by gray surfaces, temperatures in the liquid phase at the outer boundaries by transparent contours and velocities in the liquid phase at the outer boundaries by scaled vectors. 


\subsection{Heat flux and liquid phase fraction over time}

The heat flux $q^{\prime \prime}$ on the inner tube wall and the liquid phase fraction $f_{1}$ of the whole storage domain are plotted over time for each fin design in Figure 6. These results were gained by the aforementioned realistic natural convection model.

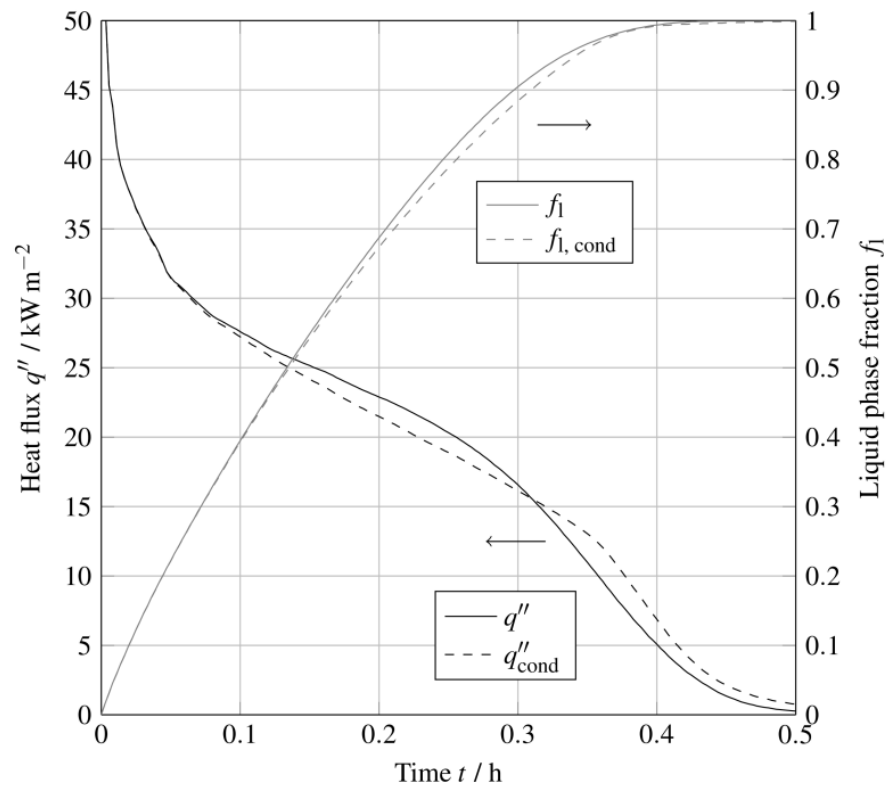

a) Axial-70 Organic

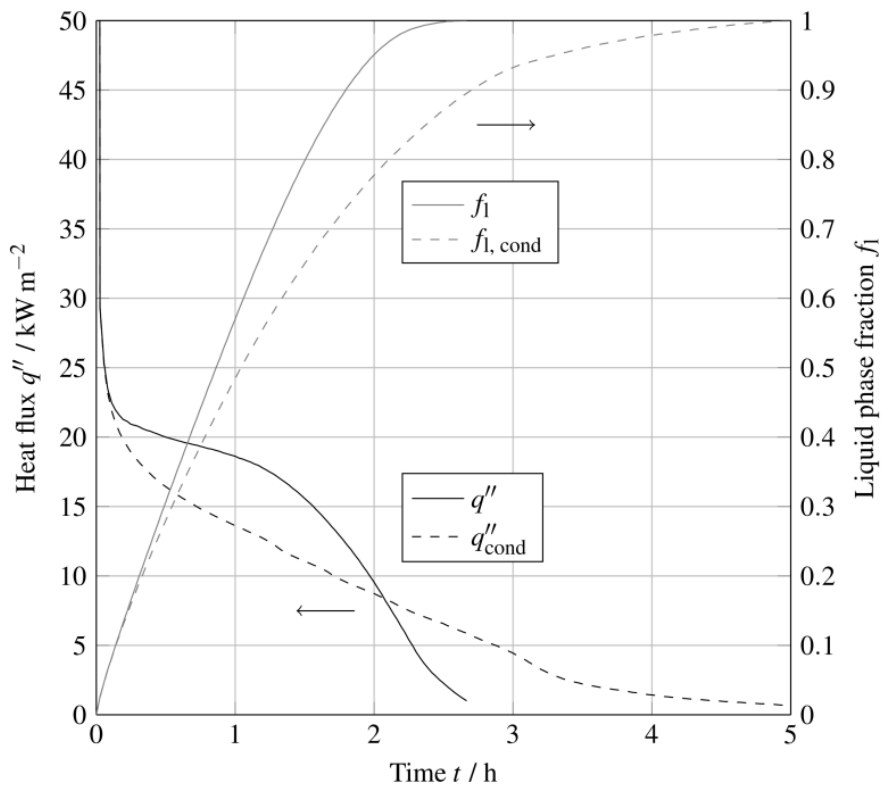

c) Axial-160 Snowflake
Additionally, the heat flux $q_{\text {cond }}^{\prime \prime}$ and $f_{\text {l,cond }}$, resulting from a hypothetical heat conduction model, are added. By comparing both results, we can already estimate the influence of natural convection. We can also see that every fin design has different levels and characteristic curves of the heat flux.

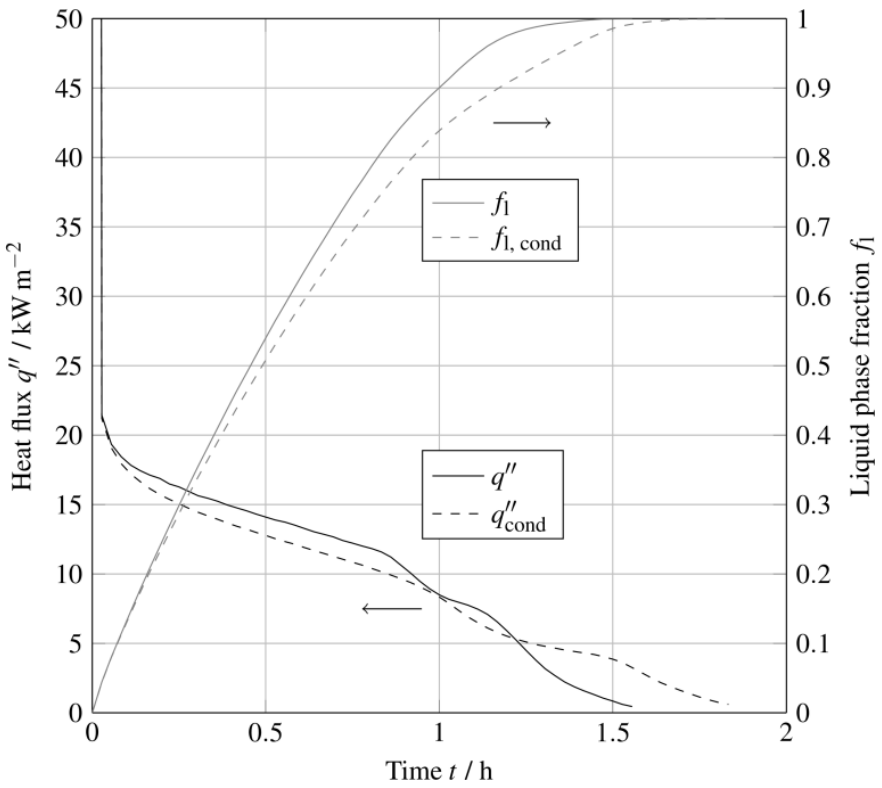

b) Radial-100 Plate

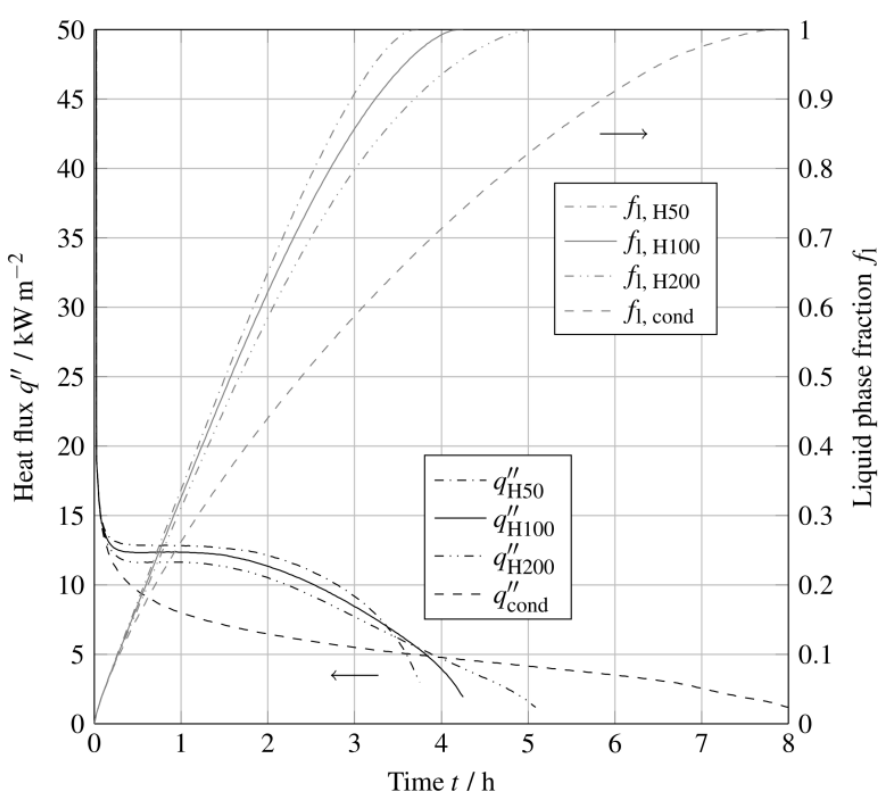

d) Axial-230 Eco

Figure 6: Heat flux $q^{\prime \prime}$ (black) and liquid phase fraction (gray) over time for each of the four designs. Results are plotted in solid lines for the full natural convection model and in dashed lines for the hypothetic heat conduction model. The fin design d) Eco was investigated not only for a height of $H=100 \mathrm{~mm}$, but also for heights $H=50 \mathrm{~mm}$ and $H=200 \mathrm{~mm}$.

For the Organic design, the power level is initially high due to a small tube spacing $D_{\mathrm{t}}$ and a high fin fraction $f_{\text {fin }}$, see Figure 6 a). But the power decreases quickly due to a relatively small capacity. Melting takes around half an hour. The exact melting times $t_{\mathrm{m}}$ are given in Table 4 . We can also observe that the melting process is dominated by heat conduction, since the curves for the natural convection and the heat conduction models are similar.

The Plate fin, see Figure $6 \mathrm{~b}$ ), has a lower heat flux $q^{\prime \prime}$ and a larger capacity due to larger tube spacing $D_{\mathrm{t}}$ and lower fin fraction $f_{\text {fin }}$, which leads to a higher melting time around one and a half hours. Although the difference between the realistic natural convection and the hypothetic heat conduction model is 
slightly more distinguished, natural convection still only has a minor impact.

The Snowflake fin with a larger tube spacing for a larger capacity has a melting time of around two and a half hours, see Figure $6 \mathrm{c}$ ). However, in this case, melting is dominated by natural convection. With the hypothetical heat conduction model, melting needs around five hours. This is also approximately the time the solidification process would need, because solidification is mostly dominated by heat conduction.

Finally, the design Eco with the largest tube spacing $D_{\mathrm{t}}$ and rather low fin fraction $f_{\text {fin }}$ was designed for a large capacity and a discharge (solidification) time of eight hours, see Figure $6 \mathrm{~d})$. This is also the time melting needs with the hypothetical heat conduction model. However, melting with the realistic natural convection model only needs around four hours in the case with height $H=100 \mathrm{~mm}$. With increasing height, melting takes slightly longer, as is seen in the case with $H=200 \mathrm{~mm}$. With decreasing height, melting takes slightly less time, as can be seen in the case with $H=50 \mathrm{~mm}$.

\subsection{Heat transfer enhancement due to natural convection}

To assess the heat transfer enhancement due to natural convection, we used the same method as described in greater detail in a previous article by Vogel et al. [21]. The idea with this method is to compare the heat flux $q^{\prime \prime}$ to the hypothetical heat flux by heat conduction $q_{\text {cond }}^{\prime \prime}$. Since the time-scale of the two models is different even for the same fin design, the heat fluxes have to be evaluated at the same liquid phase fraction. A convective enhancement factor can then be defined as the ratio of heat fluxes at the same liquid phase fraction:

$\varepsilon\left(f_{\mathrm{l}}\right)=\frac{q^{\prime \prime}\left(f_{\mathrm{l}}\right)}{q_{\text {cond }}^{\prime \prime}\left(f_{\mathrm{l}}\right)}$.

The convective enhancement factor and the heat fluxes over liquid phase fraction are plotted in Figure 7. 


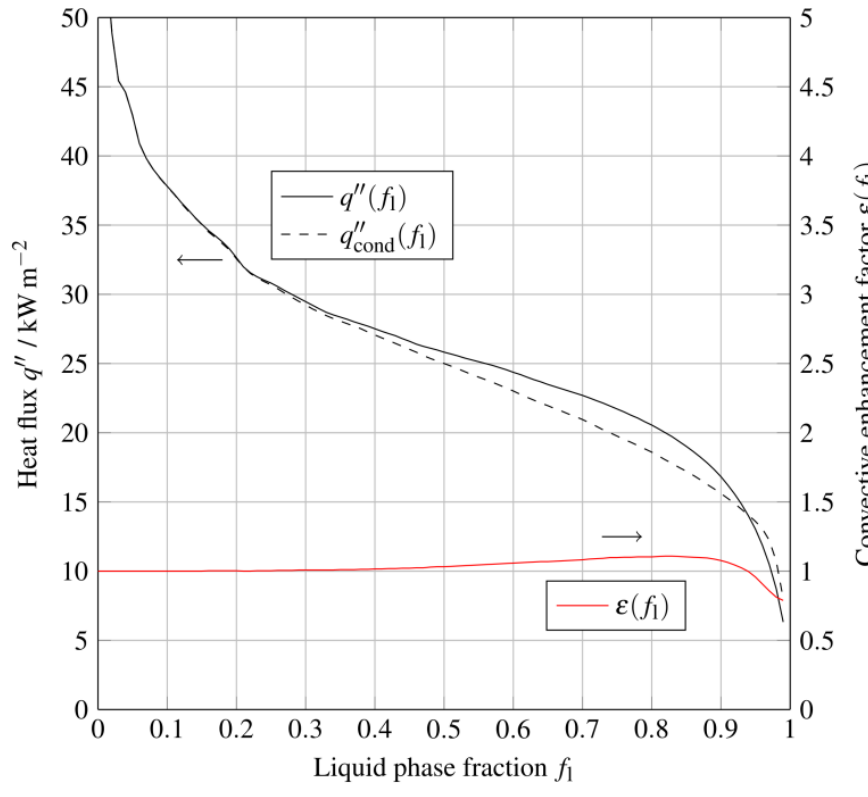

a) Axial-70 Organic

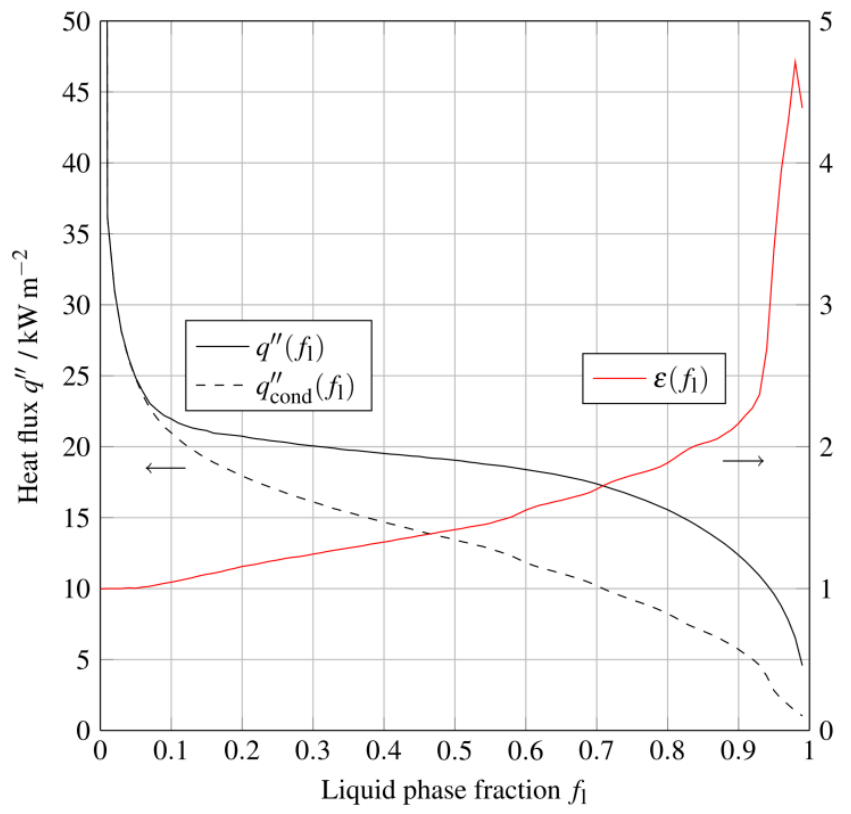

c) Axial-160 Snowflake

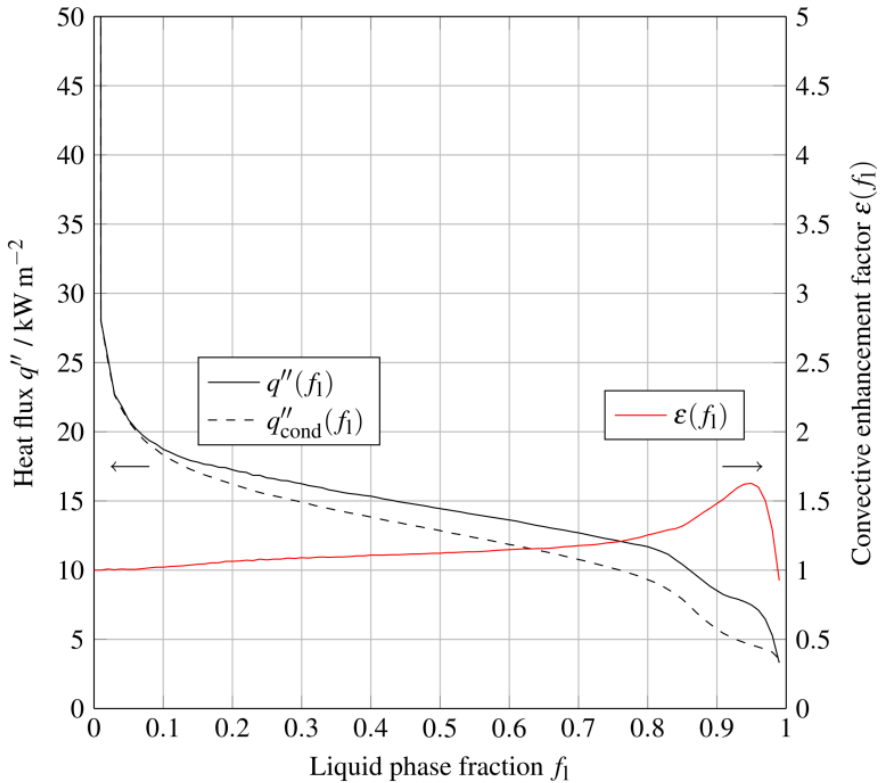

b) Radial-100 Plate

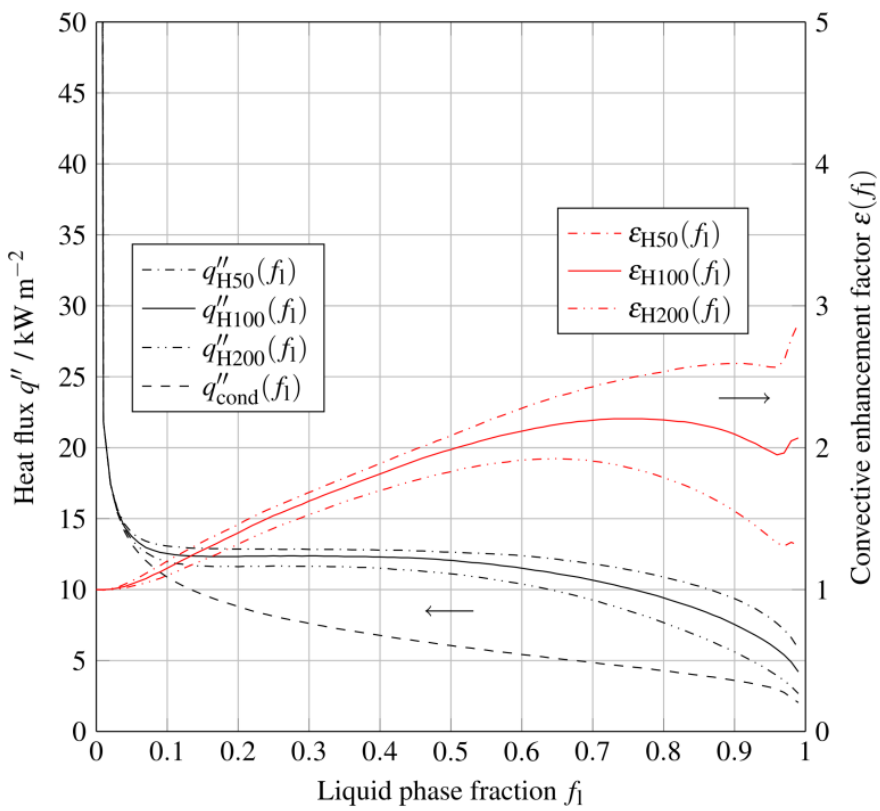

d) Axial-230 Eco

Figure 7: Convective enhancement factor $\epsilon$ (red dash-dotted line), which is the fraction of heat flux by natural convection (solid black line) to heat flux by heat conduction (dashed black line) evaluated at equal liquid phase fractions for each of the four designs.

Generally, heat transfer enhancement due to natural convection increases with the liquid phase fraction. However, natural convection induces thermal stratification and a curved phase boundary [21], which inhibits heat transfer enhancement at a later stage of melting. Therefore, there is always a more or less pronounced maximum in the curves of the convective enhancement factor $\varepsilon$.

For the Organic fin, the convective enhancement factor $\varepsilon$ is close to one throughout the melting process with a maximum value of $\varepsilon=1.1$. For the Plate fin, the convective enhancement factor is also close to one for the majority of the time with a sudden increase at the end of melting $\left(f_{1} \approx 0.95\right)$ with maximum value $\varepsilon=1.6$. We can see from Figure $5 \mathrm{~b}$ ) that natural convection begins to play a major role once the PCM between the fins is already melted and convection enhances heat transfer to the distant solid PCM outside the fins. For the Snowflake design, large values of up to $\varepsilon=4.7$ are found. While $\varepsilon$ only slowly increases at first, a sudden increase is found at the end of melting. In this case again, natural convection helps to increase heat transfer to the comparatively distant solid PCM "islands" outside the reach of the fins, compare Figure $4 \mathrm{c}$ ) and Figure $5 \mathrm{c}$ ). The fin design Eco with height $H=100 \mathrm{~mm}$ has a lower maximum value of $\varepsilon=2.2$ around $f_{\mathrm{l}} \approx 0.75$. The maximum value for case H50 is $\varepsilon=2.9$ and for $\mathrm{H} 200$ it is $\varepsilon=1.9$. The curves of $\varepsilon$, as well as $q^{\prime \prime}$, are more balanced, which originates from a favorable distribution 
of the fin throughout the domain. Natural convection then leads to a nearly constant heat flux during the melting process with this fin design.

\subsection{Maximum velocity magnitudes}

To get an idea about the velocities occurring in the liquid phase of the PCM during melting, we evaluated the maximum velocity magnitudes over time and plotted the results in Figure 8 for all of the test cases. First of all, we can observe that the flow in the Organic design is initially slow and only reaches higher values in the later stage of melting. The fin designs Snowflake and Eco obtain similar velocities at least for the same height $H=100 \mathrm{~mm}$. From the other heights $-H=$ $50 \mathrm{~mm}$ and $H=200 \mathrm{~mm}$ - we can see that the velocity magnitude strongly depends on the height with higher velocities at greater heights. The fin design Plate only leads to comparatively small velocities, which can be attributed to the small spacing between fins and the radial orientation of fins, which inhibits natural convection.
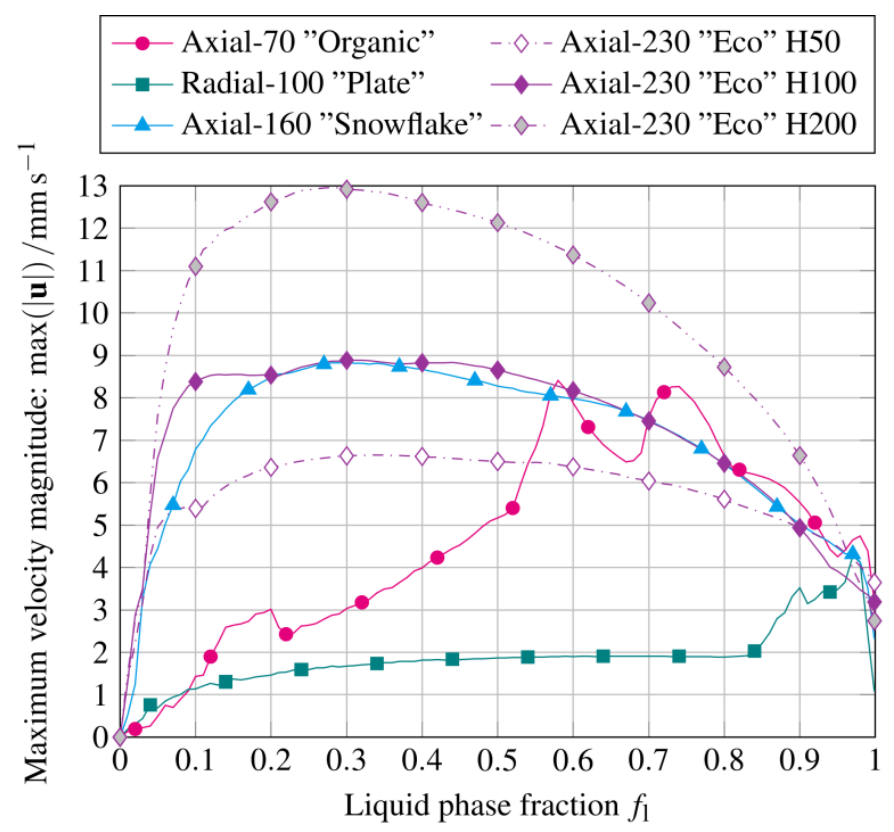

Figure 8: Maximum velocity magnitude plotted over liquid phase fraction for all six of the analyzed design parameters.

\subsection{Dimensional analysis}

The relevant dimensionless numbers of the described physical problem are the aspect ratio $A$, the Rayleigh number $R a$, the time dependent Fourier number $F o(t)$, the Stefan number Ste and the Prandtl number Pr:

$$
\begin{aligned}
& A=\frac{H}{W}, \quad R a=\frac{g \beta \Delta T l^{3}}{v_{1} a_{1}}, \quad F o(t)=a_{1} \frac{t}{l^{2}}, \\
& \text { Ste }=\frac{c_{p, 1} \Delta T}{L}=0.093, \quad \operatorname{Pr}=\frac{v_{1}}{a_{1}}=8.57 .
\end{aligned}
$$

The driving temperature difference, $\Delta T=\left(T_{\mathrm{w}}-T_{\mathrm{m}}\right)$, is between the wall and the melting point of the PCM. The characteristic length $l$ may be either the height of the PCM volume $H$ or, in analogy to melting in a rectangular enclosure, the width of the PCM volume $W$. For fin designs, we define the width $W$ as a fraction of the liquid PCM volume $V_{\mathrm{PCM}}$ and the fin surface area $A_{\text {fin }}$ :

$W=\frac{V_{\mathrm{PCM}}}{A_{\mathrm{fin}}}$.

We can then think of the width $W$ as a measure of the average space between fin branches. We thereby assume that melting between fin branches is similar to melting in rectangular enclosures.

There is an ongoing discussion on whether the width $W$ or the height $H$ should be used as the characteristic length. While research about natural convection in enclosures used the width, e.g. Elder [45], theoretical scaling analysis revealed the height as physically meaningful choice, e.g. Jany and Bejan [17]. In the end, the characteristic length may be freely chosen, as long as the aspect ratio $A$ of the enclosure is taken into account. For the present work, we calculated the dimensionless numbers with the height $H$ as well as the width $W$ as the characteristic length. The resulting scales and dimensionless groups are given in Table 4. 
Table 4: Scales and non-dimensional groups for all six of the analyzed design parameters

\begin{tabular}{cllllll}
\hline \multirow{2}{*}{ Scale or group } & $\begin{array}{l}\text { Axial-70 } \\
\text { Organic }\end{array}$ & $\begin{array}{l}\text { Radial-100 } \\
\text { Plate }\end{array}$ & $\begin{array}{l}\text { Axial-160 } \\
\text { Snowflake }\end{array}$ & $\begin{array}{l}\text { Axial-230 } \\
\text { Eco H50 }\end{array}$ & $\begin{array}{l}\text { Axial-230 } \\
\text { Eco H100 }\end{array}$ & $\begin{array}{l}\text { Axial-230 } \\
\text { Eco H200 }\end{array}$ \\
\hline$t_{\mathrm{m}} / \mathrm{s}$ & 1766 & 5498 & 9484 & 13419 & 15115 & 18210 \\
$H / \mathrm{mm}$ & 100 & 100 & 100 & 50 & 100 & 200 \\
$W / \mathrm{mm}$ & 2.8 & 5.4 & 6.7 & 12.3 & 12.3 & 12.3 \\
$A$ & 35.7 & 18.5 & 14.9 & 4.1 & 8.1 & 16.3 \\
$R a_{H}$ & $1.4 \cdot 10^{8}$ & $1.4 \cdot 10^{8}$ & $1.4 \cdot 10^{8}$ & $1.8 \cdot 10^{7}$ & $1.4 \cdot 10^{8}$ & $1.1 \cdot 10^{9}$ \\
$R a_{W}$ & $3.1 \cdot 10^{3}$ & $2.2 \cdot 10^{4}$ & $4.3 \cdot 10^{4}$ & $2.6 \cdot 10^{5}$ & $2.6 \cdot 10^{5}$ & $2.6 \cdot 10^{5}$ \\
$\frac{R a_{H}}{R a_{W}}$ & 87 & 1200 & 2900 & $6.5 \cdot 10^{4}$ & $3.2 \cdot 10^{4}$ & $1.6 \cdot 10^{4}$ \\
$F o_{H}\left(t_{\mathrm{m}}\right)$ & 0.030 & 0.093 & 0.16 & 0.90 & 0.25 & 0.077 \\
$F o_{W}\left(t_{\mathrm{m}}\right)$ & 38 & 32 & 36 & 15 & 17 & 20 \\
$S t e$ & 0.093 & 0.093 & 0.093 & 0.093 & 0.093 & 0.093 \\
$P r$ & 8.57 & 8.57 & 8.57 & 8.57 & 8.57 & 8.57 \\
\hline
\end{tabular}

Melting is initially dominated by heat conduction, but natural convection sets in as soon as the liquid layer reaches a critical size, so that the buoyancy forces due to temperature gradients can overcome the viscous forces due to boundary layers at the walls and at the liquid-solid interface. A criterion for the transition from the pure conduction regime to a naturalconvection-affected regime in rectangular enclosures was derived by Batchelor [46]. The flow is dominated by natural convection, if

$\frac{R a_{H}}{A^{4}}=\frac{R a_{W}}{A} \geq 500$.

Assuming that this criterion is also valid for our fin designs, all test cases should be dominated by natural convection except the axial design Organic, which has the smallest tube spacing $D_{\mathrm{t}}=70 \mathrm{~mm}$. This design is probably dominated by heat conduction.

The onset of turbulence for natural convection in rectangular enclosures was studied by Elder [47]. He found that the flow is laminar for

$R a_{H}=R a_{W} A^{3}<10^{10}$.

Using this criterion, all test cases are expected to be laminar. However, the Rayleigh number for the axial fin design Eco with larger height $H=200 \mathrm{~mm}$ is close to the threshold value for turbulence. So, for larger heights, turbulence is expected.

\subsection{Influence of natural convection in dimensionless form}

We continued our scaling analysis of previous publications by Vogel et al. [21] and Vogel and Bauer [31]. Both works investigated melting governed by natural convection in rectangular enclosures. With a scaled time

$$
\begin{array}{rl}
\tilde{t}_{\text {rectangular }}=0.78 & F o_{H}(t) \text { Ste } R a_{H}{ }^{\frac{1}{6}} A^{\frac{5}{4}} \\
& =0.78 F o_{W}(t) \text { Ste } R a_{W}{ }^{\frac{1}{6}} A^{-\frac{1}{4}},
\end{array}
$$

the melting process was represented in dimensionless form, either with the height $H$ or the width $W$ as characteristic length.
For this investigation, the idea was to apply the same scaling procedure to fin designs. Therefore, we retained the exponents and only adjusted the constant factor so that the scaled time again ranges to 1 as average for all test cases:

$$
\begin{aligned}
\tilde{t}=7.7 F o_{H}(t) \text { Ste } & R a_{H}{ }^{\frac{1}{6}} A^{\frac{5}{4}} \\
& =7.7 F o_{W}(t) \text { Ste } R a_{W}{ }^{\frac{1}{6}} A^{-\frac{1}{4}}
\end{aligned}
$$

The liquid phase fraction is drawn over time in Figure 9 a) and over scaled time in Figure $9 \mathrm{~b}$ ). Although we found a slightly better scaling effect when further optimizing the exponents of $R a$ and $A$, we decided to keep the same exponents as in our previous investigations on rectangular enclosures [21,31] to obtain a more general correlation while accepting a slight decrease in accuracy. 

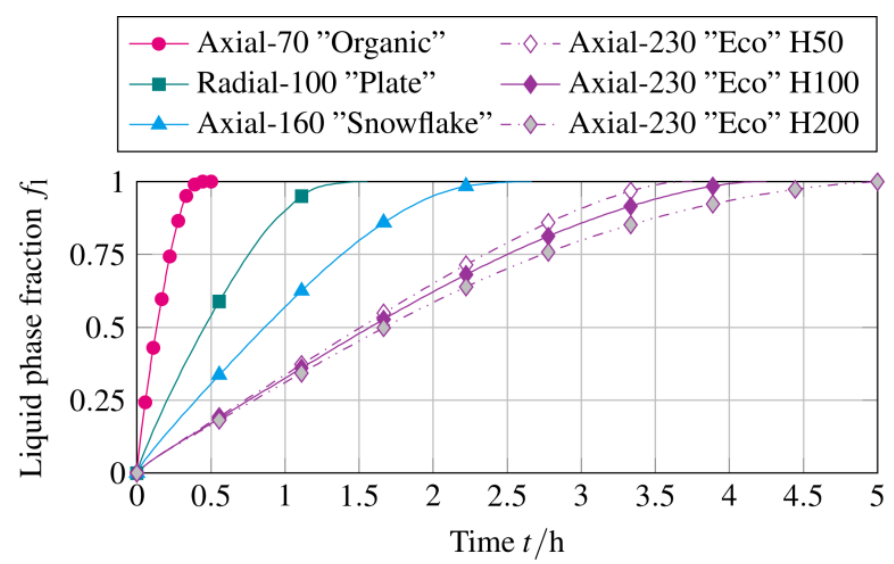

a) Plot over time

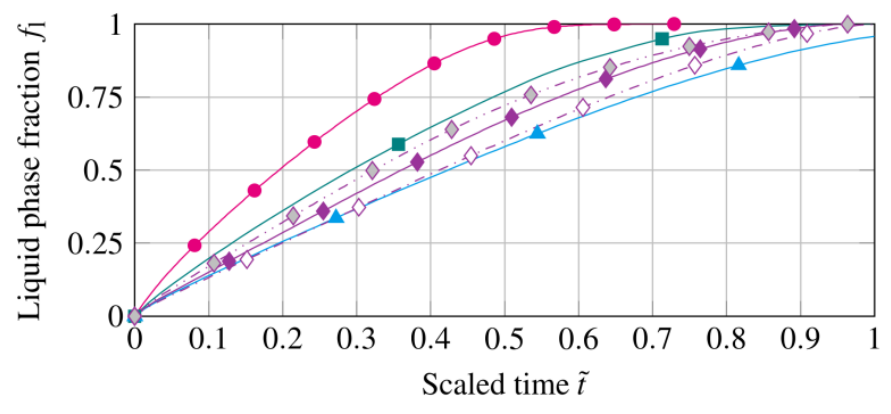

b) Plot over scaled time

Figure 9: Liquid phase fraction plotted for each of the six parameters a) over time and b) over scaled time.

Finally, to judge the impact of natural convection on the melting process for a specific fin design in dimensionless form, we used the convective enhancement factor already shown in Figure 7. As in Vogel et al. [21], we calculated the mean values of the convective enhancement factor for every test case. These are plotted over scaling factors in Figure 10.

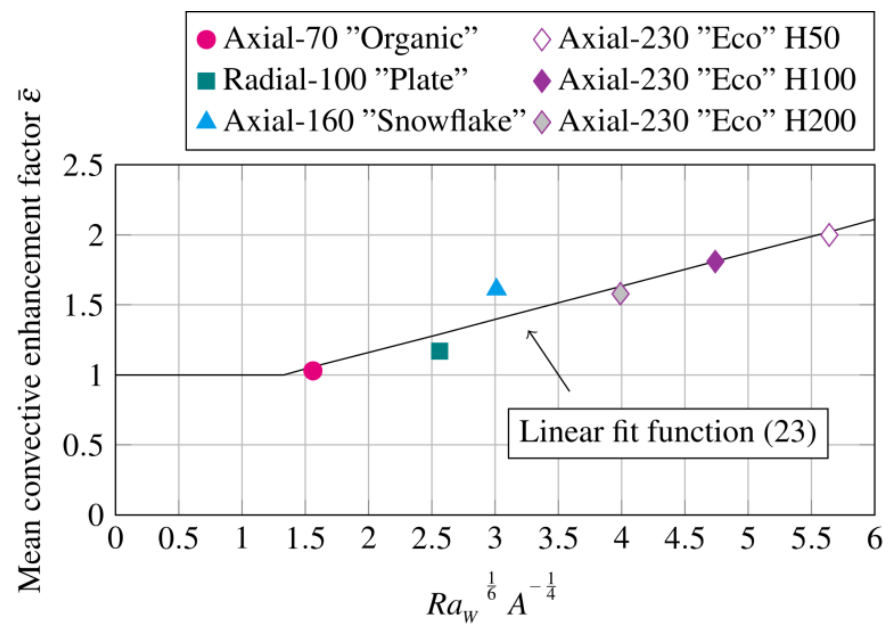

Figure 10: Mean convective enhancement factor $\bar{\varepsilon}$ plotted over scaling factors for each of the design parameters, including the linear fit function (23).

We used the Rayleigh number $R a_{\mathrm{W}}$ and the aspect ratio $A$ as scaling factors, and retained the exponents from previous studies. Alternatively, we can express the scaling factors using the height $H$ as the characteristic length: $R a_{W} \frac{1}{6} A^{-\frac{1}{4}}=$ $R a_{H}^{\frac{1}{6}} A^{-\frac{3}{4}}$.

From the data points of the mean convective enhancement factors for the different test cases, we calculated a linear fit function, analogously to Vogel et al. [21]:

$$
\bar{\epsilon}=\left\{\begin{array}{cl}
1 & \mathrm{Ra}_{W}{ }^{\frac{1}{6}} \mathrm{~A}^{-\frac{1}{4}}<1.33 \\
0.24\left(\mathrm{Ra}_{W}{ }^{\frac{1}{6}} \mathrm{~A}^{-\frac{1}{4}}\right)+0.69 & \mathrm{Ra}_{W}{ }^{\frac{1}{6}} \mathrm{~A}^{-\frac{1}{4}} \geq 1.33
\end{array},\right.
$$

The linear fit function was found by minimizing the sum of least square errors with a residual of 0.07 using the Microsoft Excel solver add-in. The fit function was cut off at the minimum possible value $\bar{\epsilon}=1$, which occurs at $\mathrm{Ra}_{W}{ }^{\frac{1}{6}} \mathrm{~A}^{-\frac{1}{4}}=$ 1.33. The fit function is also limited by the laminar flow regime, see Equation (20).

This correlation is intended to roughly approximate the impact of natural convection during melting of a PCM in a shell-and-tube system with extended fins. It shows how natural convection increases with increasing Rayleigh number $R a_{W}$ and decreasing aspect ratio $A$. For example, fin designs with lower fin fraction $f_{\text {fin }}$ and lower fin surface area $A_{\text {fin }}$ will have a higher characteristic width $W$ and hence higher heat transfer enhancement by natural convection. Moreover, geometries with larger height $H$ will have a higher aspect ratio and therefore lower heat transfer enhancement by natural convection.

\section{Discussion}

In the present study, we introduced an analogy to transfer the scaling procedure of natural convection in rectangular enclosures from previous research [21] to the not yet established case of natural convection within spaces between fin branches in more complex fin geometries. The question is the extent to which this analogy is valid. The results of the scaling procedure are shown in Figure 9. We showed that the scaling procedure works out-of-the-box, but not as well as in the case of the rectangular enclosure. An explanation for this is that the compared fins were designed with differing design goals. Obviously, the Plate fin is a large exception within compared fins. But, despite the common assessment that natural convection would be completely hindered in this fin design, the evaluation in Figure 7 b) shows there actually is an enhancement of heat transfer that fits in the scaling analysis. Also, the axial fins are dissimilar. The design Snowflake was one of the earliest axial fin designs for LTES and was optimized more for the manufacturing process and less for the heat transfer characteristic. It has larger spaces of PCM absent of fin structure that lead to a lower heat transfer rate at the beginning, but enhanced heat transfer due to stronger natural convection at the end of melting, see Figure $7 \mathrm{c}$ ). This may also be due to asymmetries in the design, resulting in a less steady development of natural convection over the melting process. Finally, the fin design Organic has very narrow spaces between fin branches and therefore it is dominated by heat conduction with a CEF near to unity, see Figure 7 a). Only for this test case did the scaling procedure for natural convection only partially apply and lead to larger deviations. A similar result was 
already found in the previous investigation on rectangular enclosures [21] for a case that was also dominated by heat conduction.

An uncertainty is the validity of the equations (19) and (20) for a system with phase change, since the correlations were derived for single phase systems. We still may use them in the following approximate sense: the height and width of the liquid phase region will permanently change during melting. However, at a certain point, the liquid region will be nearly as high and/or wide as the height $H$ and width $W$. As a result, assuming the flow of a single phase fluid is governed by natural convection or turbulence, then the flow in the liquid phase of a phase change material is probably also governed by natural convection or turbulence at some point during the melting process.

An interesting question is the validity of the scaling procedure and the resulting equation (23) for larger heights, since large scale LTES systems have been designed with up to $H=6 \mathrm{~m}$ [13] and even larger heights seem feasible. The present parameter study, however, includes only heights up to $H=0.2 \mathrm{~m}$, due to the large computational effort involved. The upside is that we tested three height variations in this study, further 7 height variations in the previous study on rectangular enclosures [21] and validated the numerical modeling and scaling procedure [31]. Hence, it is plausible that the presented correlation also scales up to larger heights. The validity of the presented correlation is still restricted until we analyze larger heights. To include larger heights, we would have to think about turbulence modeling, since equation (20) predicts turbulent flow for $H>0.41 \mathrm{~m}$ in the present case.

\section{Conclusions and outlook}

The impact of natural convection on melting of a phase change material was investigated in four different fin designs with varying tube distance, fin volume fraction and fin type. Three different heights were modeled for one of the fin designs to additionally investigate the influence of height.

The visualization of the melting process gave a detailed insight into the different characteristics of the natural convection mechanism that occurred during melting.

The convective enhancement factor was calculated for every fin design to analyze the impact of natural convection on melting. An analogy for the characteristic width of a finned tube to a rectangular enclosure was used to transfer previous methods and results of a dimensional analysis. A scaling procedure delivers adequate results in consideration of the diverse fin designs and types.

A linear fit function for the mean convective enhancement factor is presented that allows the estimation of the melting process considering natural convection. With it, natural convection may be incorporated in the design process of latent thermal energy storage systems to optimize the charging time. This allows for an improved and simplified design process for latent thermal energy storages, which has not been possible to date.

There are two overall results worth considering: firstly, the impact of natural convection increases with larger continuous areas of storage material, i.e. larger tube spacing and smaller fin volume fraction. Hence, the decrease of heat transfer rate with reduced amount of fin material is partially compensated.
Secondly, large fin heights lead to decreased enhancement of heat transfer by natural convection. A resulting design principle is to segment long axial fins into shorter sections of $H \approx 0.1 \mathrm{~m}$, which could be realized by inserting one plate fin between every pair of adjacent axial fin sections.

To continue the present investigation and to increase the accuracy of the derived correlation, more fin designs should be examined. Also, more variations in height and especially larger heights should be examined.

\section{Acknowledgements}

The analyses discussed here are based on fin geometries developed in various projects. We would like to thank the German Federal Ministry of Economic Affairs and Energy for partially funding the work within the DSG-Store project (Contract No. 0325333A and 0325333D) and the TESIN project (Contract No. 03ESP011A) as well as the German Federal Ministry for the Environment, Nature Conservation and Nuclear Safety for partially funding the work within the ITES project (Contract Nos. 03UM0064 and 03UM0065) and the REAL-DISS project (Contract No. 16UM0090). These projects gave the basis that allowed for these comparisons.

We would especially like to thank Bernd Hachmann for his continued interest and work in the development of fin geometries. In addition, the authors are grateful to Dan Bauer and Stefan Zunft for their support.

\section{References}

[1] IPCC. Climate Change 2014: Synthesis Report. Contribution of Working Groups I, II and III to the Fifth Assessment Report of the Intergovernmental Panel on Climate Change [Core Writing Team, R.K. Pachauri and L.A. Meyer (eds.)]. Geneva, Switzerland: 2014.

[2] International Energy Agency (IEA). Technology Roadmap: Energy storage. 2014.

[3] Cabeza LF. Advances in Thermal Energy Storage Systems. Amsterdam: Woodhead Publishing; 2015. doi:10.1016/C2013-0-16453-7.

[4] Laing D, Bauer T, Breidenbach N, Hachmann B, Johnson M. Development of high temperature phase-change-material storages. Appl Energy 2013;109:497-504. doi:10.1016/j.apenergy.2012.11.063.

[5] Walter H, Beck A, Hameter M. Transient Analysis of an Improved Finned Tube Heat Exchanger for Thermal Energy Storage System. Proc. ASME 2015 9th Int. Conf. Energy Sustain., 2015, p. 1-14.

[6] Garcia P, Rougé S, Nivelon P. Second test campaign of a pilot scale latent heat thermal energy storage - Durability and operational strategies. AIP Conf Proc 2016;1734:50016. doi:10.1063/1.4949114.

[7] Agyenim F, Hewitt N, Eames P, Smyth M. A review of materials, heat transfer and phase change problem formulation for latent heat thermal energy storage systems (LHTESS). Renew Sustain Energy Rev 2010;14:615-28. doi:10.1016/j.rser.2009.10.015.

[8] Jegadheeswaran S, Pohekar SD. Performance enhancement in latent heat thermal storage system: A review. Renew Sustain Energy Rev 2009;13:2225-44. doi:10.1016/j.rser.2009.06.024. 
Agyenim F, Eames P, Smyth M. A comparison of heat transfer enhancement in a medium temperature thermal energy storage heat exchanger using fins. Sol Energy 2009;83:1509-20. doi:10.1016/j.solener.2009.04.007.

[10] Liu M, Saman W, Bruno F. Review on storage materials and thermal performance enhancement techniques for high temperature phase change thermal storage systems. Renew Sustain Energy Rev 2012;16:2118-32. doi:10.1016/j.rser.2012.01.020.

[11] Gasia J, Miró L, Cabeza LF. Materials and system requirements of high temperature thermal energy storage systems: A review. Part 2: Thermal conductivity enhancement techniques. Renew Sustain Energy Rev 2016;60:1584-601. doi:10.1016/j.rser.2016.03.019.

[12] Laing D, Bauer T, Lehmann D, Bahl C. Development of a Thermal Energy Storage System for Parabolic Trough Power Plants With Direct Steam Generation. Proc. ASME 2009 3rd Int. Conf. Energy Sustain., 2009.

[13] Johnson M, Vogel J, Hempel M, Hachmann B, Dengel AJ. Design of High Temperature Thermal Energy Storage for High Power Levels. Sustain Cities Soc 2017;35:1-6. doi:10.1016/j.scs.2017.09.007.

[14] Dhaidan NS, Khodadadi JM. Melting and convection of phase change materials in different shape containers: A review. Renew Sustain Energy Rev 2015;43:449-77. doi:10.1016/j.rser.2014.11.017.

[15] Bareiss M, Beer H. Experimental investigation of melting heat transfer with regard to different geometric arrangements. Int Commun Heat Mass Transf 1984;11:323-33. doi:10.1016/0735-1933(84)90060-5.

[16] Benard C, Gobin D, Martinez F. Melting in rectangular enclosures: experiments and numerical simulations. J Heat Transfer 1985;107. doi:10.1115/1.3247506.

[17] Jany P, Bejan A. Scaling theory of melting with natural convection in an enclosure. Int J Heat Mass Transf 1988;31:1221-35. doi:10.1016/0017-9310(88)90065-8.

[18] Farid MM, Husian RM. An electrical storage heater using the phase-change method of heat storage. Energy Convers Manag 1990;30:219-30. doi:10.1016/0196-8904(90)90003$\mathrm{H}$.

[19] Shatikian V, Ziskind G, Letan R. Numerical investigation of a PCM-based heat sink with internal fins. Int J Heat Mass Transf 2005;48:3689-706.

doi:10.1016/j.ijheatmasstransfer.2004.10.042.

[20] Shatikian V, Ziskind G, Letan R. Numerical investigation of a PCM-based heat sink with internal fins: Constant heat flux. Int J Heat Mass Transf 2008;51:1488-93. doi:10.1016/j.ijheatmasstransfer.2007.11.036.

[21] Vogel J, Felbinger J, Johnson M. Natural convection in high temperature flat plate latent heat thermal energy storage systems. Appl Energy 2016;184:184-96.

doi:10.1016/j.apenergy.2016.10.001.

[22] Pointner H, de Gracia A, Vogel J, Tay NHS, Liu M, Johnson $\mathrm{M}$, Cabeza LF. Computational efficiency in numerical modeling of high temperature latent heat storage:

Comparison of selected software tools based on experimental data. Appl Energy 2016;161.

doi:10.1016/j.apenergy.2015.10.020

[23] Muhammad MD, Badr O. Performance of a finned, latentheat storage system for high temperature applications. Appl Therm Eng 2017;116:799-810.

doi:10.1016/j.applthermaleng.2017.02.006.

[24] Pizzolato A, Sharma A, Maute K, Sciacovelli A, Verda V. Design of effective fins for fast PCM melting and solidification in shell-and-tube latent heat thermal energy storage through topology optimization. Appl Energy 2017;208:210-27. doi:10.1016/j.apenergy.2017.10.050.
[25] Pizzolato A, Sharma A, Ge R, Maute K, Verda V, Sciacovelli A. Maximization of performance in multi-tube latent heat storage - Optimization of fins topology, effect of materials selection and flow arrangements. Energy 2019.

doi:https://doi.org/10.1016/j.energy.2019.02.155.

[26] ANSYS Inc. ANSYS 15 Fluent User's Guide 2015.

[27] Johnson M, Vogel J, Hempel M, Dengel A, Seitz M, Hachmann B. High temperature latent heat thermal energy storage integration in a co-gen plant. Energy Procedia, vol. 73, Düsseldorf: Elsevier B.V.; 2015, p. 281-8. doi:10.1016/j.egypro.2015.07.689.

[28] Laing D, Bauer T, Steinmann W-D, Lehmann D. Advanced high temperature latent heat storage system - design and test results. 11th Int. Conf. Therm. Energy Storage, Stockholm, Sweden: 2009.

[29] Hübner S, Eck M, Stiller C, Seitz M. Techno-economic heat transfer optimization of large scale latent heat energy storage systems in solar thermal power plants. Appl Therm Eng 2016;98:483-91. doi:10.1016/j.applthermaleng.2015.11.026.

[30] Vogel J, Thess A. Validation of a numerical model with a benchmark experiment for melting governed by natural convection in latent thermal energy storage. Appl Therm Eng 2019;148:147-59.

doi:https://doi.org/10.1016/j.applthermaleng.2018.11.032.

[31] Vogel J, Bauer D. Phase state and velocity measurements with high temporal and spatial resolution during melting of $n$ octadecane in a rectangular enclosure with two heated vertical sides. Int J Heat Mass Transf 2018;127:1264-76. doi:10.1016/j.ijheatmasstransfer.2018.06.084.

[32] Inc A. ANSYS 15 Fluent Theory Guide 2015.

[33] Voller V, Prakash C. A fixed grid numerical modelling methodology for convection-diffusion mushy region phasechange problems. Int J Heat Mass Transf 1987;30:1709-19. doi:10.1016/0017-9310(87)90317-6.

[34] Brent AD, Voller VR, Reid KJ. Enthalpy-Porosity Technique for Modeling Convection-Diffusion Phase Change: Application to the Melting of a Pure Metal. Numer Heat Transf 1988;13:297-318. doi:10.1080/10407788808913615.

[35] Voller VR, Swaminathan CR. General Source-Based Method for Solidification Phase Change. Numer Heat Transf Part B 1991;19:175-89. doi:10.1080/10407799108944962.

[36] Carman PC. Fluid flow through granular beds. Chem Eng Res Des 1997;75:S32-48. doi:10.1016/S02638762(97)80003-2.

[37] Shmueli H, Ziskind G, Letan R. Melting in a vertical cylindrical tube: Numerical investigation and comparison with experiments. Int J Heat Mass Transf 2010;53:4082-91. doi:10.1016/j.ijheatmasstransfer.2010.05.028.

[38] Johnson M, Hübner S, Braun M, Martin C, Fiß M, Hachmann B, Schönberger M, Eck M. Assembly and attachment methods for extended aluminum fins onto steel tubes for high temperature latent heat storage units. Appl Therm Eng 2018;144:96-105.

doi:https://doi.org/10.1016/j.applthermaleng.2018.08.035.

[39] Bauer T, Laing D, Tamme R. Overview of PCMs for Concentrated Solar Power in the Temperature Range 200 to 350 ${ }^{\circ}$ C. Adv Sci Technol 2010;74:272-7.

[40] Bauer T, Laing D, Tamme R. Characterization of sodium nitrate as phase change material. Int J Thermophys 2012;33:91-104. doi:10.1007/s10765-011-1113-9.

[41] Bauer T, Laing D. Sodium Nitrate for high temperature latent heat storage. 11th Int. Conf. Therm. Energy Storage, 2009, p. $1-8$.

[42] Janz GJ, Allen CB, Bansal NP, Murphy RM, Tomkins RPT. Physical Properties Data Compilations Relevant to Energy Storage. II. Molten Salts: Data on Single and MultiComponent Salt Systems. NSRDS-NBS. U.S. Dept of 
Commerce; 1979.

[43] Versteeg HK, Malalasekera W. An introduction to computational fluid dynamics: The Finite Volume Method. 2nd ed. 2007.

[44] Patankar S. NUMERICAL HEAT TRANSFER AND FLUID FLOW. Hemisphere Publishing; 1980.

[45] Elder JW. Laminar free convection in a vertical slot. J Fluid
Mech 1965;23:77. doi:10.1017/S0022112065001246.

[46] Batchelor GK. Heat transfer by free convection across a closed cavity between vertical boundaries at different temperatures. Q Appl Math 1954;12:209-33.

[47] Elder J. Turbulent free convection in a vertical slot. J Fluid Mech 1965;23:99-111. 